\title{
Developing Flow and Heat Transfer in Strongly Curved Ducts of Rectangular Cross-Section
}

by

Gaymond Yee*

and

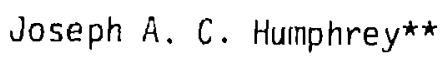

Lawrence Berkeley Laboratory

University of Cal ifornia

Berkeley, California 94720

* Science Applications, Inc.

San Leandro, California

* Department of Mechanical Engineering

University of California

Berkeley, California 94720

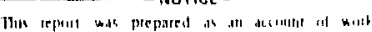

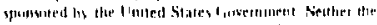

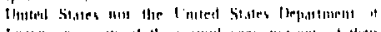

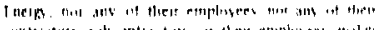

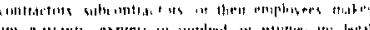

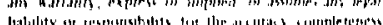

Tare

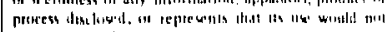

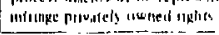


Index

Abstract

Nomencla ture

i i

Introduction

1

Calculation Procedure and Test Cases

5

Case Studies, Results and Discussion

Conclusions

18

Acknowledgements

20

References

Figure Captions

23

Figures 
ABSTRACT

A numerical study of heat transfer in $90^{\circ}$, constant cross-section curved duct, steady, laminar flow is presented. The work is ailled primarily at characterizing the effects of duct geometry on hent transfer by considering, especially, the role of secondary motions during the developing period of the flow. However. due consideration has also been given to varying initial conditions of velocity and temperature at the entrance section to the duct. In addition, an rassessment is made of the relative contrihutions of individual duct. walls to heat transfer in the flow. It is found that, in general, heat transfer increases with Dean number with the largest transfer rates occurring through the duct side walls and outer-curvature wall. Duct geometries with aspect ratio greacer or smaller than unity have weaker secondary motions and are less effective for heat trarisfer. Similarly, plug-flow entrance profiles for velocity retard the develnpment of cross-stream flow thus inhibiting a significant contribution to hent transfer. It is concluded that short ducts with strong curvature $\left(2 R c / D_{H}<10\right)$ and intense secondary motions can be as effective for heat transfar as longer ducts which are less strongly curved.

Calculations are based on fully elliptic (in space) forms of the transport equations governing the flow. They are of engineering value and are limited in accuracy only by the degree of computational mesh refinement. A comparison with calculations based on parabolic equations has been made and it is shown how the latter can lead to erroneous results for strongly curved flows. 
NOMENCLATURE

a curved duct width

b curved duct breadth

$c_{p}$ heat capacity at constant pressure

$C_{f}$ friction corfficiens at : plome

Cp pressure loss coefficient at : plane

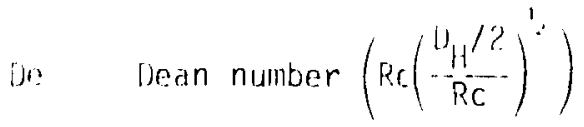

il curved duct hydroulic diameter ( $4 x$ surface/perimeter)

h perimeter average heat transfer coefficient at iplane $(\bar{r} /(T w-\bar{T}))$

k. thermal conductivity

ivu perimeter average Nusselt number at t plane $\left(\bar{h}_{H} / k\right)$

$r$ pressure at a point in the flow

Pr surface average pressure at $\$$ plane
Pr Prandti number $u c / k$

"ref l' it. T" mine"

is heat flux at a point on a wall

4 ferimeter averayn heat flux at ip plane

$r$ radial direction in cylindrical coordinates

$\therefore$ inmer curvature wall

$r_{11}$ outer curvature wall

Ro duct radius of curvature $\left(\left(r_{j}+r_{0}\right) / 2\right)$

Re Reynolds number $\left(\frac{D_{H} \cdot V_{B}}{H^{\prime}}\right)$

$T$ value of temperature at a point in the flow

T mass average temperature at $\$$ plane

$T_{i n}$ inlet temperature 
$T_{W}$ wall temperature

$|\vec{V}|$ modulus of secondary motion vector velocity at a point in the flow

$V_{B}$ surface average longitudinal velocity at $\$$ plane

$v_{\phi}$ longitudinal velocity component

$v_{r}$ radial velocity component

$v_{z}$ axial velocity component

2 axial direction in cylindrical coordinates

$\theta$ non-dimensional temperature at a point in the flow $\left(\frac{T_{W-}}{T_{W^{-}}{ }^{T}}\right)$

${ }_{B}$ non-dimensioral mass average temperature at $\phi$ plane $\left(\frac{\bar{T}-T_{i n}}{T_{i n}}\right)$

H viscosity

$\rho$ density

Tw wall shear stress

p longitudinal direction in cylindrical coordinates 
INTRODUCTION

Considerable effort has been expended on the experimental measurement and calculation of flows in curved ducts of rectangular cross-section, principally because of the practical significance of such flows. Curved duct qeometries frequently arise in enqineering configurations where, besides providing a necessary conduit for the fluid, it may be required to enhance heat and/or mass transport processes. In curved ducts this is achieved mainly due to the prolonged residence times of fluid elements which must move along spiraling paths as they rovolve in the main (longitudinal) flow direction. Thus, the centrifugal force-radial pressure gradient imbalance acting on slow moving fluid near the side walls of the duct induces a motion of the fluid aiong the side walls and directed from the outer towards the inner curvature wall. In turn, faster moving fluid in the core reqion of the flow moves along the conter (sylumetry) plane of the duct, being directed from the inner to the outer curvature wall. The cross-strean motion just described is commoniy referred to in the literature as secondary motion of the "first kind" or, simply, secondary motion [1]. It is obvious that the extent to which heat and mass transport can be enhanced in curved duct flows will be a strong function of the intensity and spatial variation of the secondary motion.

Even though experimental works on curved duct flows abound (a recent review may be found in [2]), data availability for engineering purposes is often defficient or simply inadequate. Whereas considerable work has been carried out to obtain useful design correlations for pressure losses and friction coefficients [3], there is no equivalent body of knowledge describing three-dimensional velocity, enerqy and mass transport phenomena 
in sufficient detail and over a wide enough range of relevant dimensionless flow parameters. That this should be the case may be understood by considering the phenomenal task refuirar. unly to obtain detailed measureIlents of three velocity components for different conditions of duct aspect ratio. Dean number, radius ration $2 R C / D_{H}$ (for turbulent flows [4]) and, for developing flows, at various duct deflection angles. It is not surprising to find therefore that avaliable velocity desta is mainly restricted to the longitudinal component direction and that the majority of heat and mass transer studies have focused on cases of fully developed curved dur:t flcw with houndary conditions of specific relevance to the particular rases investiqated.

Whereas experimentation in curved duct qeometries may be laborious (and complex). it is possible, in principle, to compute these flows quite accurately in the laninar regime. This has been shown by, amonq others, Cheng and Akiyamr [5], Cheng, Lin and Du [6] and Joseph, Smith and Adler [7] for fully developed flow and by Shia and Sokhey [8] and Humphrey, Taylor and Whitelaw [9] for developing flow. Of the above only the procedure used by Humphrey, et. al. [9] is based on fully elliptic forms (in space) of the equations of motion. Calculations for turbulent flow regime have been performifd hy Pratap and Spalding [10] using a semi-elliptic numerical procedure. However, the agreement between calculations and measurements of velocity is less satisfactory in this case. Although the authors attribute the discrepancies to failings in the model of turbulence employed in the calculations, it is possible that their neglect of higher order curvature terms in the equations of motion may have contributed to the mider-prediction of secondary velocity components.

Experimental investigations of heat transfer in curved duct flows have been described by, for example. Kreith [11], Mori, Uchida and Ukon [12] 
and Yang and Liao [13] while corresponding numerical calculations are reported by Cheng and Akiyama [5] and Cheng, et. a1. [6]. Except for the experimental works of Kreith [11] and Yang and Liao [13] (in turbulent regine) the remaining studies deal with the problem of fully developed laminar flow. In general, these and similar studies show that heat transfer in curved duct flow is enhanced relative to that occurring in straight ducts, with transfer rates at outer curvature walls being typically 2 to 5 times larger than corresponding values at inner walls. Non-dimensionalized vilues of temperature profilas show trends similar to those displayed by the longitudinal velocity component. With maximum values shifted towards the nuter curvature will. Equivalent information appears to be lacking for the caso of developing laminar flow. Especially noticeable is the dearth of information for ducts with relatively strong curvature (small radis ratio: 2 Pac/li 10$)$ where spatial Ellipticity in the flow field may be pronouncer.

The present study is directed toward providing (through numerical computatimi recessary fluid merianical and heat transfer data for developinc steady iaminar flow of an incompressible fluid in strangly curved ducts with $90^{\circ}$ deflection angle. The calculations are of engineerincicuracy and allow a relative comparison of duct performan.e and jetailed flow characteristics as a function of relevant dimensionless parameters, such as Dean and Reynolds number, aspect ratio and radius ratio. [ecause of the numerical approach in the study it has been possible to examine an extensive combination of geometrical confiqurations for various initial and boundary conditions for temperature and velocity. The experilifital equivalent of this (or a similar) study would be exceedingly Taborious, time consuming and expensive to perform. This substantiates 
the need for developing and applying calculation procedures which can be used with confidence, relatively easily and (by comparison to experiments) at moderate costs. The numerical procedure used in this study is presently the basis for similar calculations in turbulent single and two-phase flow to be reported at a later date. 


\section{CALCILLATION PROCEDURE AND TEST CASES}

The calculation procedure used to compute the flows in this study has already been described in [9]. Extension of the procedure to arbitrary orthoyonal coordinate qeometries and. especially, its application to developing curved nipe flows of strong curvature have been documented by Humbry $[?: 2$ ? The lactur reference contains general finite difference furres at ine conservation equations for mass, momentum and transferable

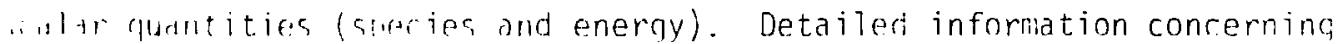
me drerivatinn of the difforence equations, their numerical solution and results for varinur tast cases solved to evaluate the procedure are raported in the above twi references and in [2]. This section presents a sullimy of the essartial features characterizing the calculation methor toagther with a description of its application to flows in curved ducts with neat tranfer. Some of the results for two calculated test.

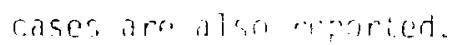

Guatione, Libury Conditions and Procedure for Numerical Solution

$\because$ is conservation, momentum and enerqy equations for three-dimensional. strate. ircompressible laminar flow in curved ducts of cylindrical ceometry cirrenponding to Fig. I are given by

$$
\begin{aligned}
& \frac{r v}{r r}+\frac{1}{r} i v+\frac{i v}{i z}+v_{r}=0 .
\end{aligned}
$$

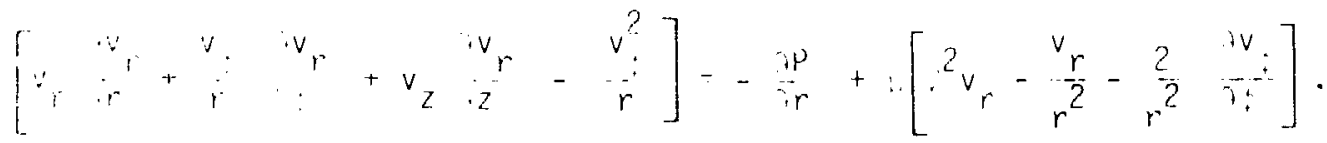

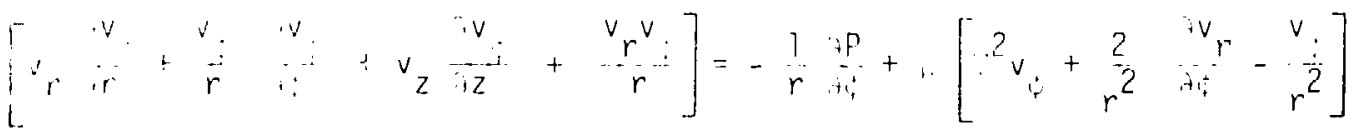




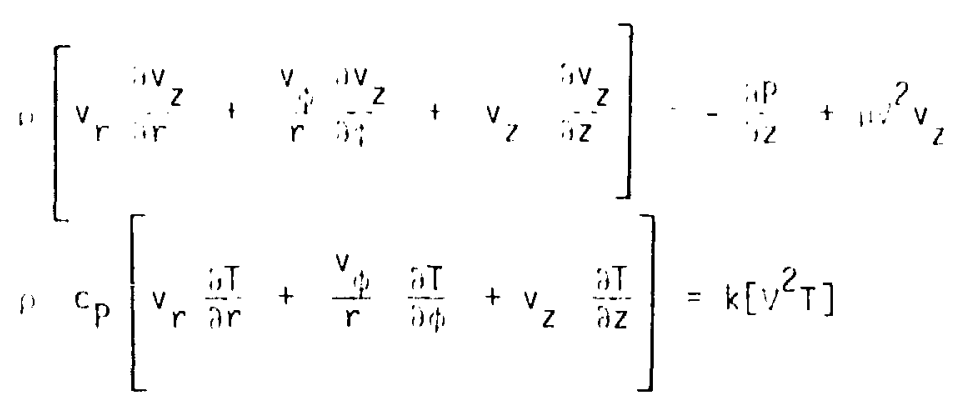

where

$$
y^{2}=\frac{i^{2}}{i r^{2}}+\frac{1}{r} i r+\frac{1}{r^{2}} \frac{\lambda^{2}}{\partial y^{2}}+\frac{i^{2}}{i z^{2}}
$$

It is required to solve (1)-(5) together with various comt inations of the boundary conditions as shown below:

Inlet plane $\left(i=0^{\circ}\right)$.

$v_{r}=v_{z}=0, v_{\phi}=$ plug flow or developed duct flow

$T=$ constant or $f(r)$

Exit plane (all $r$ and $z$ at $\left.\phi=90^{\circ}\right)$.

$\frac{\partial v_{r}}{\partial \phi}=\frac{\partial v_{z}}{\partial \phi}=\frac{\partial v_{\phi}}{\partial \phi}=\frac{\partial T}{\partial \phi}=0$

with overall continuity of mass and energy imposed.

Side walls (all p at $z= \pm b / 2$ and $r=r_{i}, r_{0}$ ).

$v_{r}=v_{z}=v_{\phi}=0$

$T=$ constant or $f(\phi)$ at specified walls

$q=0$ at specified walls

Symmetry plane $(a 71 r$ and $\phi$ at $z=0)$.

$v_{z}=\frac{\partial v_{r}}{\partial z}=\frac{\partial v_{\phi}}{\partial z}=\frac{\partial T}{\partial z}=0$ 
The conditions imposed for velocity at the inlet and exit planes have been carefully discussed in [14]. It is shown there that the curved duct has a minimal effect on the incoming fluid stream, thus allowing a fairly arbitrary prescription of the velocity distribution at: $=0^{\circ}$. While not strictly correct, the velocity condition at the exit plane $\left(:=90^{\circ}\right)$ is a good approximation and is substantiated by the satisiactory agreement found here (and in $[9,14]$ ) between measurements and calculations.

The finite difference equations are obtained by integrating (7)-(5) over volume elements on "cells" discretizine the flow domain. The velocity combonts, pressure and temperature wh the dependent variables computed on a nuriber of staggered, intercomected grids, eas of which is acsotided with a specific variable. The general form of the finite difference expression is given by

$$
\therefore p=\left(\begin{array}{c}
6 \\
\cdots \\
i-1
\end{array} A_{i} i_{i}+S_{0}\right) \int_{i=1}^{6} A_{i}
$$

wherr ip a a ity corponent, pressure or temperature) is the variable soives $i$ a a position $P$ in the discretized flow domain. The $A_{i}$ coofficients are determined at the cell surfaces and represent the combined contributions of convection and oiffusion to the balance of $\phi$. Other contributions arising from pressure, body forces and temperature (sources or sinks) are contained in $S_{0}$. Detailed forms for $S_{0}$ in variable property flows are available in [15].

Solution of the system of finite difference transport equations with apropriately differenced boundary conditions is achieved by means of a cyclic series of predictor-corrector operations as described in $[9,14]$. Briefly, the method involves using an initial or intermediate value of the 
pressure fifald to colve for nil intermedinte velority field. A pressure

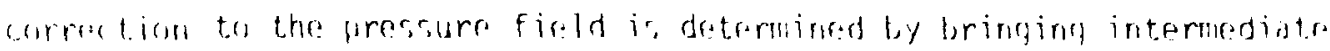
velocitier, into conformity with continuity. Corrections, to the pressure and velocity fields are applied and the anerqy equation is solved for $\mathrm{T}$ In flows whre energy and mommentum are not. linked throusin temperature

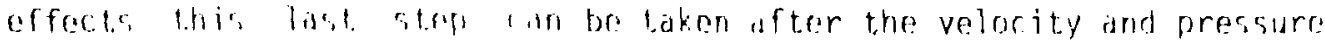
fields have been determinred). The above stops are repedted until some pre-eritablishod convergence criterion is sidtisfied.

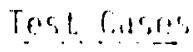

Ixtensive testing and an evaluntion of the calculation proredure for predicting flows without hrat transfer have been documented in [2] and reported in part in $[9,14]$. It has been shown in these references that. fully olliptic, three-dimensional computations of sufficient accuracy for enginerering purposes can be obtained on unequally spaced qrids as coarse as $12 \times 12 \times 20(r \times z \times 4)$. The predictions presentod here and in the following we tims have been performed on a $12 \times 15 \times 20$ mesh. While finer

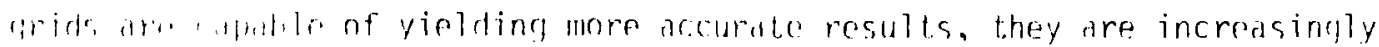
more cxpmive to compute. Whereas numerical schemes based on parabolic or semi-elliptic forms of the transport equations will handle equivalent and finer calcutation meshes at significantly less cost., for flows such as the ones of interest here where curvature effects can be pronounced, it is not mosihle to determine a priori if less than fully elliptic: equations are iustified. For two interesting examples involving flow reversal in curved irts. See $[9,14]$.

Profiles of lonaitudinal velocity and pressure, respectively calculated $\therefore$ : : iptir and parabolic forms of the transport equations, are shown - : $\left.: y^{\prime} ;-c\right)$ where they are compared with experimental velocity data from 
[9]. The parabolic calculations were reditiy obtained by modifuira tre elliptic procedure of $[9,14]$ as expidined in, for examite, Launder [16]. Thr. plots allow a relative comparison between the two approaches for a duct of relatively strong curvature (case 1 in Table 1). It car be seen that the w? intic results yield significantly bettur predictions of longitudinal velocity (ard cross-strean components noi ihwor hero), especially hetween

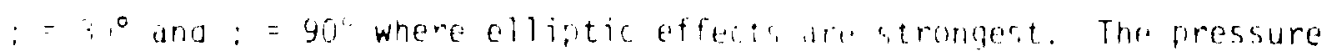
profile in Fic. $2-c$ show, in part, the ressom for the discrepancy. In the

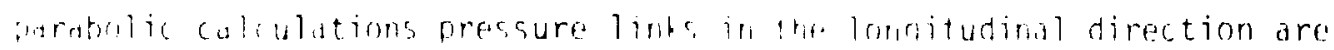

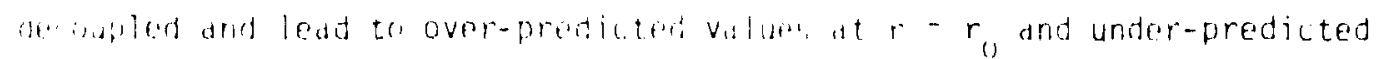

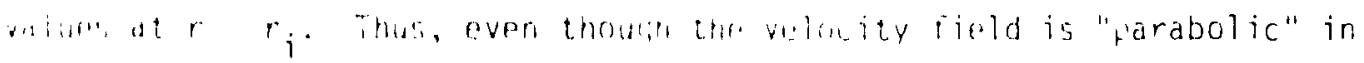
1ha 1! contains no reversea flow some, ellipticity in thi pressure field is still strong and must be dealt with accordingiy.

Auritimal indicutions of the differences which can arise between Cisfitic and parduolic computational approaches in stronciy curved flows

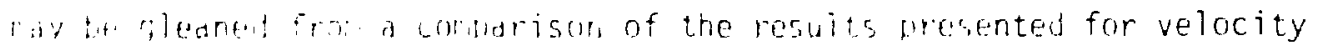
: uphents and tenterdure in Figs. 4-a ard $4-h$, respectively. The figures ..rid: , ind of calculated resuits at: $=90^{\circ}$ which are significantly dissirsicis. in particular, the parabolic langitudinal velocity contours show : ign speed fluid trapped near the outer curvature wall between the side Writ and ymmetry plane. This effect contradicts experimental evidence in $[9]$ and is due to the over-prediction of an unfavorabie longitudinal pressure gradient at the outer curvature wall. The over-prediction also chilins why secondary motion at the outer radius wall, near the symmetry plane, is directed away from the wall and into the flow. Of course, aifferences in the temperature contours will arise because of the differences ir. veiocity and will be in error as well. It may be concluded that for 


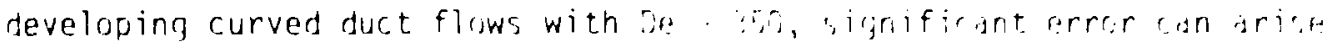

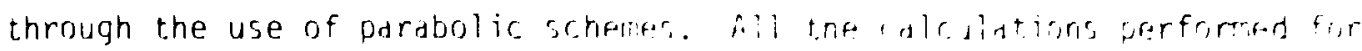
the parametric study presented in tre next section hive teen based in fully elliptic ioms of the traneport erqutions as ijan in ! ij-16j. As a check for the validity uf tha colculation procenture in the

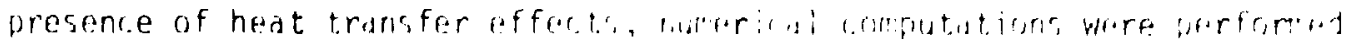

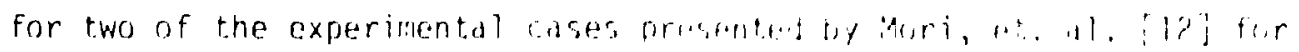

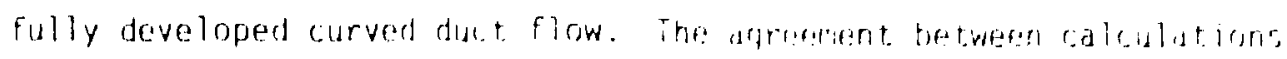

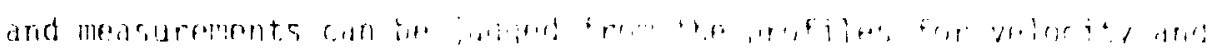

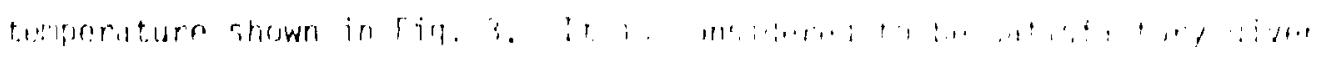

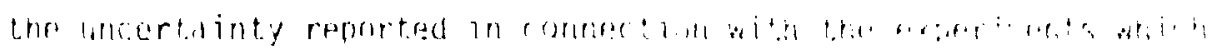

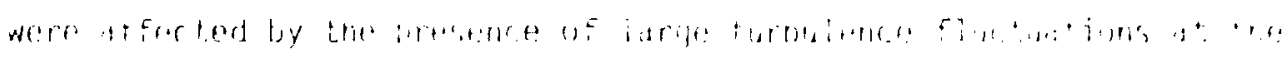

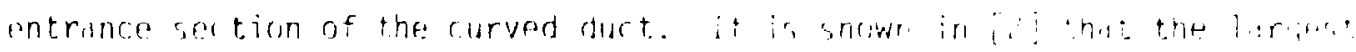

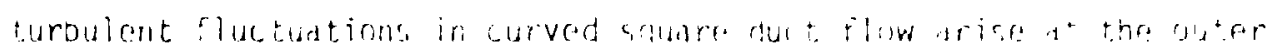

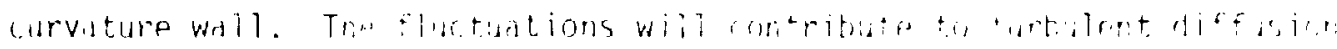

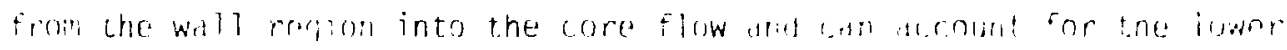

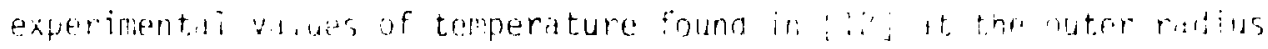
w.: : . . .

Ricorousiy, the procedure should be tested for its capacity to predict. Huiventuiil and heat transfer effects during the developing perind of duct iow. nowever, the authors are unaware of any experimental data in curved ducts which would serve for such a comparison. Notwithstanding, calculations performed for developing temperature profiles in straight duct flow show excellent agreement with experimental measurements and analytical results. For this and more detailed discussion of the test cases reported here see Yee $[17]$. 


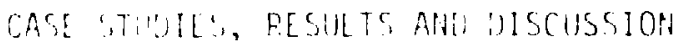

A surmary of the case studies and bunditions calculated for thic investigation is presented in tabulated form in Table 1. From the tahle it will be seen that various curved duct genmetrits were combined with

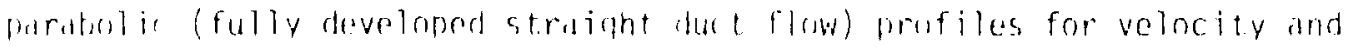

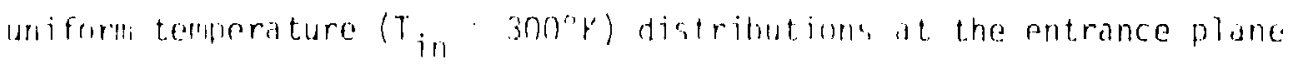
!: n'). The affects of varying initial tomporature and velocity distrituation wore also invertibutod. Fimblly, the effects of heating

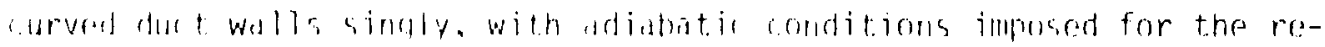

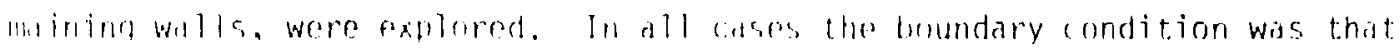
af cometani wall tomporature $\left(T_{w}=350 \%\right)$ excent for where the adiabatic comblion was ronfurced. Although mo calculated here, variable wall tamproblurr or variahlo (or constant) hert flux conditions could have just.

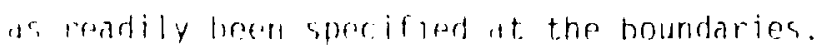

Imromipre. ible, constant property $(\mathrm{Pr}=1.0)$ flow was assumed for the widulations un! is an ucceotable supposition for the rance of temperatures con-

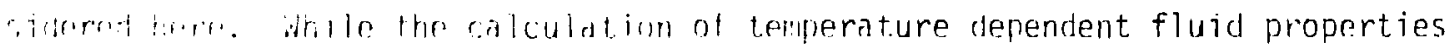
ie. in indard feature in the numerical procedure, it does increase the cost (" uredictions through adritional storage and computing time requirements. Vil: 11 values for storage and $C P$ times for the case studies presented here vere ino $k_{8}$ and 235 seconds, respectively on a C.DC 7600 . The averaqe time required ner node $x$ iteration for all runs was $1.44 \times 10^{-5} \mathrm{CP}$ seconds.

The remainder of this section is devoted to the presentation and and discussion of some of the results calculated for the test cases in Table 1. The procentation is subdivided according to the topic of incerest both for edse of discussion and to enhance the separate roles of the various waralite s affecting heat transfer in curved duct flow. 


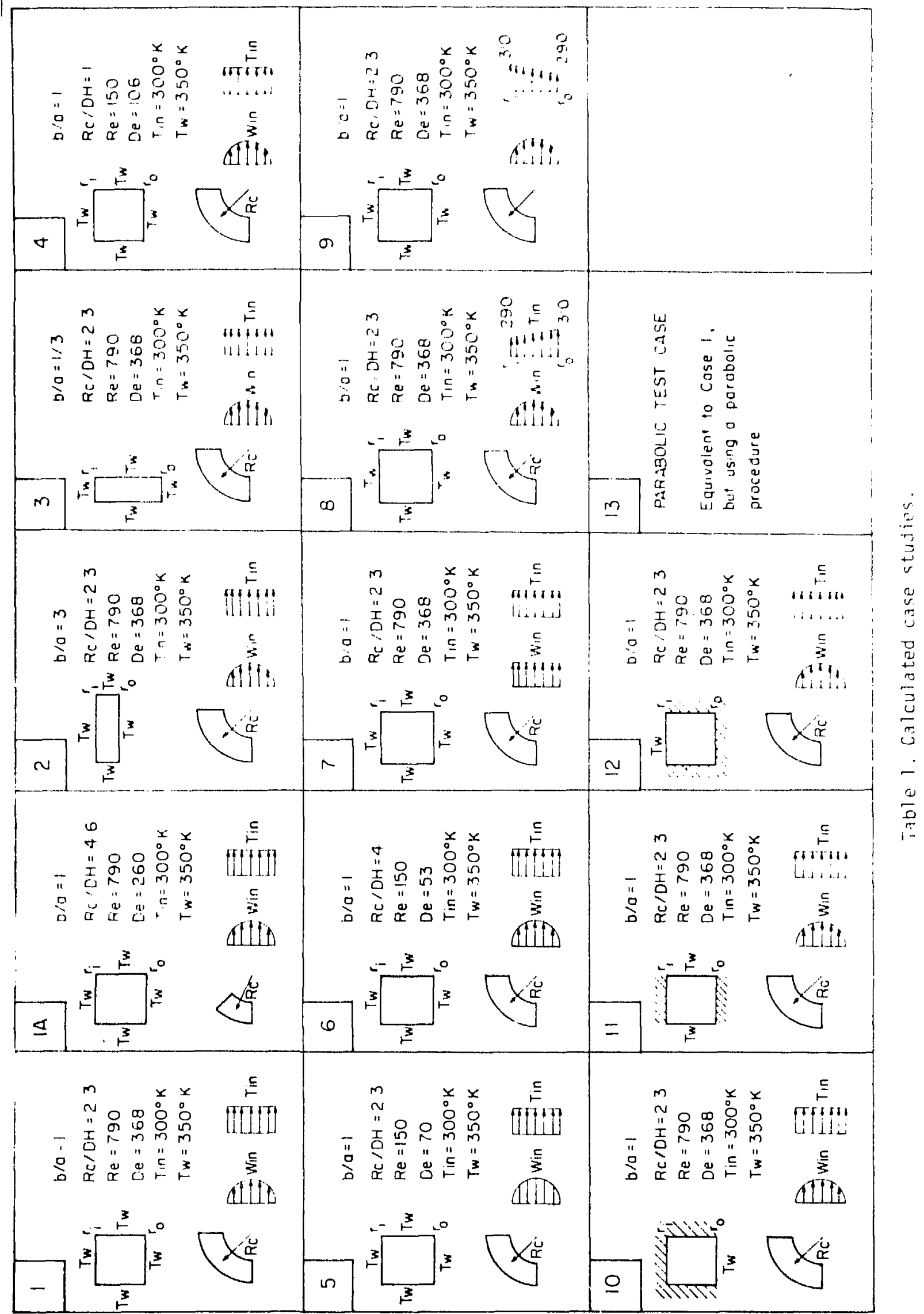


Velocity and Ternendure Distributions

plots of non-dimensinnal velocity and temperature distributions are given in Fig. $4(a-h)$. Longitudinal velocity and temperature are shown in the form of equal-value contours wherear the cross-strean motion is indicated in vectorial form.

linend ande (:).

The distributions shown in the figures are typical of the bulk of the moults and illustrate clearly the importunt role played by secondary motions

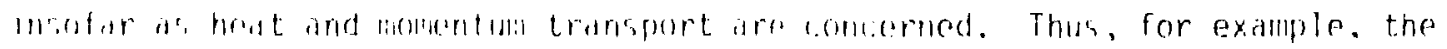
sefuence shown in lia. A-it,be provides a cloar impression of the way the flow and temperature fields evolve to produce maximum values in the resplet tive distributions displaced toward the outer-radius walt. The similurity between lonqitudind velocity and temperature contours is ifribini hut not curprosing in view of the convective nature of the flow. The rmergy find is ancoupled from the momentum field and in all cases novlues, in a monner dictedted primarily by the fluid mechanics.

nerect ratio $(b / a)$

The effect of varying aspect ratio ma be showr by a relative comparison at it,.., 1-i, d,e. It is immediately obvious that the vector plots for irosi-itrean velocity differ considerably depending on the aspect ratio. For $b / n=1$ the secondary motion is relatively high in the region of the inner-cuivature $\left(r=r_{j}\right)$ and side $(z=b / 2)$ walls, whereas for $b / a=3$ it is high at all three walls but localized mainly in the region of the side wall. For $b / a=1 / 3$ the cross-stream flow is intense along both the duct symintiry olane and side walls but, by comparison, is relatively weak at the inner- and outer-rurvature walls. Longitudinal velocity and temperature 
contours show distributions corresponding to the serse of the secoridary motion. For $b / a=1 / 3$ it is worth rellarking on the peak vis ue of longitudinal velocity which has been displaced from the duct symetry plane whence it evolved. A corresponding peat in the temperaturn distribution is not observed. In addition, for thir lart cace, iongitudinal velocit:

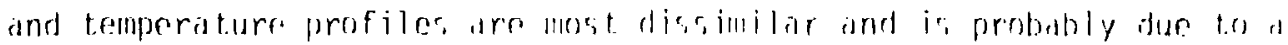
relatively larme contribution to hedt: termsfer through onduction alomy the z axis.

Velereily entrincen condition.

The effect of a plug flow entrance condition may be assessed by comparime figs. 4-c and $f$. Secondary flow evolves considorably mere slowly in the case of a flat profile entrance condition and is to be expectod since the boundary liyers on the side walls, where the transverse pressure gradient has its strongest effect, are initially very thin. As a consefuence both tho lompitudinal volocity and temperature develop sibuly also. Nithiouh not shown here, the lomitudinal velocity for this cise was obsirvest to develop a potential-flow-like appearance nver the first 20 to 30 deqrees in the duct. While lhis effect is hardly noticenble at : - gon, remmants of its presence may be detected in the temperature profiles which display double maxima near the inner-radius wall.

Individually heated walls.

Fiqure 4-g shows temperature distributions at $90^{\circ}$ for three cases in Table 1 where only one of the two curved walls or both of the side walls were heated while keeping the remaining walls adiabatic. The fluid mechanics of these cases are identical to Figs. 4-a, b and $c$ but the manner in which the temperature fields evolve are strikingly different. In all cases the 
calculations show graphically how the reesondury antion scosess ware fluid from the vicinity of the heated wall and convects it in the serise of the secondary motion. It would appear that this is achieved most successfully for case 11 with heat. rlowing into the duct through the side walls, The point that emerges clearly from the comparison is that heat transfer rater through the three types of whlls, present in curved duct flow can, arod in general will, differ markedly dependirg on flow ronditions, georetrical chardeterictics and fluid propertifes.

Pressure loss $\left(C_{p}\right)$ and Friction $\left(C_{f}\right)$ roefficients.

Profiles for the pressure loss and friction coefficients corresponding to the case studies in Table 1 are qiven in Fiys. $5(a)$ and $(b) . C_{p}$ is seen to decrease with increasing duct angle, and decreasing De, and (froll the trend in the results at $:=1.5$ radians) with decreasing b/a. The $C_{p}$ curve for the plug flrw entrance profile is also piotted for comparison with the other ciases.

In all iares the friction coefficient at the outer wall $\left(r=r_{0}\right)$ increase, (at least initially) with increasing duct angle. However, the rate of increase is largest for $b / a=1$ and smallest for $b / a=1 / 3$. High values of $C_{f}$ at $r=r_{0}$ are initially favored by low values of De but the reverse is true for $\$ 1.2$ radians. At the inner curvature wall $C_{f}$ appears to be relatively insensitive to changes in De and for $\phi \geq .7$ is largest for $b / a=3$. The potential flow profiles show $C_{f}$ decreasing at $r=r_{0}$ and increasing at $r=r_{i}$, respectively and is due to the boundary layer growth nccurring on these walls.

\section{Variation of temperature and Nusselt number.}

Figures $6-a, b$ and $c$ show the effects of duct geometry, flow characteristics and duct entrance conditions on normalized temperature and 
Nusselt number, respectively. In the plots the Nusselt number has been calculated from

$$
\left.N_{u}-{ }_{k}^{-h}\right]_{H}
$$

where th is the (local) heat transfer corfficiont averaged over the duct perimiter at it duct angle: : Thus,

$$
n-q /\left(T_{w}-\bar{T}\right)
$$

where o $i$. the (irerifeter) averaged heat flux at the : plane and $T_{w}$ and $T$ wh the wat inporaturn and average flow temperatures, respectively, at the salle comeitudinal position.

ilife curves in Fig. 6 -a all show $\bar{N} u$ increasing asymptotically with duct wro-length, after an initial and rather abrupt period of decay. The ...itia de rease in Mu is due to the relatively weak mixing effect of the commary motion during this stage of the flow. However, as the flow develops and the intensity of the secondary motion increases, heat transfer $i$, anharced and Nu increases with : The minina in the curves are seen i. dejerrid on the vislue of De and, in general, Nu increases with increasing ive. Initislly, the averane temperature of fluid in the ducts appears to be insensitive to variation in the De number. Eventually, however. 
secondary motions in the shorter but more strongly curved duct

(De 106) enhance heat transer to the point. where a definite trend

in the lempe ature profiles emierges. It. may be concluded the refore

that, for certain conditions, short ducts, with interise secondary motion can

transfer as much heat or more compared to ducts of longer length but with

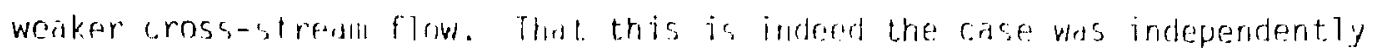
confirmed by performing total hoat balances for cases 1 ard $1 \mathrm{~A}$ in Table 1. Thus, for conditions of refual are length, 1. ls tillfes more heat was added to the duct with highor De.

From Fig. F-b it is seen that Nu is highest for $1 / \mathrm{d}=1$ for: .4 radians. It would appear that initial heat transfer gains through increasmd surface area are everibually offset. hy redections duf to weater cross-strean

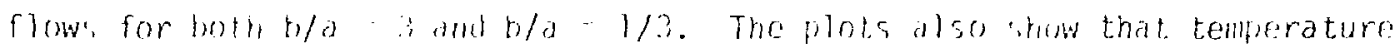
gradiente at the aloter radius wall have d inore pronounced effect on the rate of hate transfer than corresponding gradion l'a at the inner wall. This is partiy are to a surface effect but also to the presence of higher gradients of velocity at the outer radius wall.

In order to assess the relative contributions to heat transfer dising from separate duct walls during flow development, calculations were performed for the conditions corresponding to cases 10-12 in Table 1 . The results for $\overline{\mathrm{N}} u$ and " $\mathrm{B}$ are shown in Fig. 6-C. If allowance is made for the difference in hi jost rates of heat transfer occur through the side and outer radius wails in curved duct flow. This result is linked to the high values of secondary motion which arise. especially in the vicinity of the side walls, and is the cause for the pronounced maximum in the Nu plot corresponding to case 11. By 
compa"ison similar variations and maximum values of $\bar{N} u$ are less for the case of heat transfer through the inner curvature wa11. Energy balances for these three cases show that the total heat added to the duct heated through the outer wall was 1.58 times larger than that added to the duct heated through the inner wall. In turn, the total heat added to the duct heated through the side walls (allowing for the fact that there were two) was 1.0? times larger than that added to the duct heated through the outer wal1. 
CONCLIJSIONS

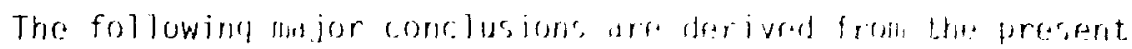
study:

1. Secondary mot ions in developine curved duct flow arn laregely rerponsible for anhanced rister, of heat trancfer after an initial period transpires to ollow signifirame development of the cross-stredm flow. In the bresent sludy thie beriod corresponded to a bend angle of $30^{\circ} \cdot$ : $^{\circ}$. $50^{\circ}$ approximately.

2. Short ducts with strong curvature my transfor as much or nore heat (to a moving fluid in which the secondary motion is intense) ar longer ducts which are not are ctrongly curved (and in which the secondary motion is weaker).

3. Higher rates of heat transfer are favored by larife De, b/a ' 1, parabolic velocity entrance conditions, and large temperature and velocity gradient. conditions at outer curvature and side walls, respectively.

4. For a plug-flow entrance velocity condition initial heat transfer rates are large but are subsequently reduced (quite considerably) due to the much slower development of the crossstream flow.

5. Whereds high values of De number favor large hedt transfer rates. the advantage must be weighed aqainst corresponding increases in friction losses. 
6. Blows in curved duets with strome curvature rexuire a fully Elliptic numerical treatment to vinld satisfactory computations. Calculations based on paratolis forme of the transport equations can produce erroneous results.

In general, the study shows that heat transfer in developing curved dat. Hallinar flow can be wefully and comphensively investigated through numerical computation of finite difference transure equations. The

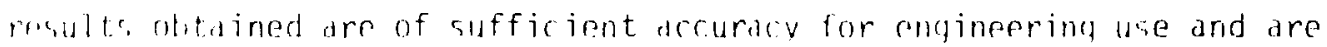

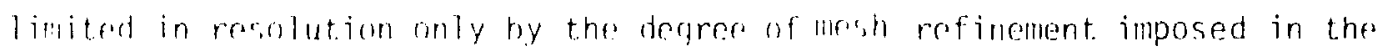
calculations. Equivalont experiments would he laborious, time consuminy and expensive to porform.

The r.diculation procedure used for this work is presently the basis for turbulent single and two-phise flow predictions in curved duct geometries. Because of the hioh turbulence fluctuations observed at the curved and side walls in these flows [?], it. is anticipated that contributions through turbulent. diffusion of particles and/or heat will significantly influmire sidior transport even though the fluid mechanics appear to be dictuler primarily by pressure gradient and body force field effects. 


\section{ACKNOWLEDCEEMENTS}

Financial support for the numerical calculations performed during the course of this work was provided by the division of Materids sciences, Offire of Basic Enerny sciencer, 15. S. Department of Energy under contract number W-7M05-ENG-4a. The authors welcome the opportunity to exprers their appreciation for this support. We are alse grateful to Mr. R. Wylia for providing the results corresponding to the parabolic flow test case. 
REFERENCES

1. BRAOSHAW, P., ed., Turbulence, 2nd ed., Vol. 12, Topics in Applied Physics, Springer-VerTag, New York, 1978, pp. 118-123.

2. HUMPHREY, J.A.C.. "Flow in Ducts with Curvature and Roughness," Ph.0. Thesis, Iniversity of London, 1977.

3. WAR[D-SMITH, A.1.. "Pressl.re Losses in Ducted Flows," Butterworth, Lonton, 1977.

4. ITO, H, "Friction Factors for Turbulent Flow in Curved Pipes," Trans. ASME, J. Bas. Enq., Vol. 11, 1959, pp. 123.

5. CHENG, K.C., and AKIYAMA, M., "Laminar Forced Convection Heat Transfer in Curved Rectanqular Channels," Int. J. Heat. Mass Transfer, Vol. 13, $1370,0.471$.

6. CHENC, K.C., LIN, R.C. and OII, J.W., "Graetz Problem in Curved Rectangular Channels with Convective Broundary Conditions - The Effert of Secondary Flow nn Liquid Solidification - Free Zone." Int. J. Heat Mass Transfer. Vol. 18, 1975, p. 996.

7. JOSEPH, G., SMITH,E.P., and ADLER, R.J., "Numerical Treatment of Laminar Flow in Helicaliy Coiled Tubes of Square Cross-Section," A.I.Ch.[.J., Vol. 21, No. 5, 1975, p. 965.

a. GHIA, K.N. and SOKHFY, J.S., "Laminar Incrompressible Viscous Flow in Curved Ducts of Rectangular Cross-Sections," Trans. ASME. J. Fluids. Eng. 1, Vol. 99 , 1977, pp. 540-648.

9. HIMPIPEY, J.A.C., TAYLOR, A.M.K., and WHITELAW, J.H., "Laminar Flow in a Square Duct of Strong Curvature," J. Fluid Mech., Vol. 83, Part 3, 1977, pp. 509-527.

10. PIBATAP, V.S. and SPALDING, D.B., "Numerical Computation of the Flow in Curved Ducts." Aeronaut. Quart., Vol. 26, 1975, P. 219.

11. KREITH, F., "The Influence of Curvature on Heat Transfer to Inconpressibie Fluids," Trans. ASME, Vol, 77, 1955, p. 1247.

12. MORI, Y., UCHIDA, Y., and UKON, T., "Forced Convective Heat Transfer in a Curved Channel with a Square Cross-Section," Int. J. Heat Mass Transfer. Vol. 14, 1971, p. 1787.

13. YANG, J.W. and LIAO, N., "Turbulent Heat Transfer in Rectangular Ducts with $180^{\circ}$ Bend," Proceedings of the 5 th International Heat Transfer Conference, J.S.M.E., 1974, p. 169. 
32.

14. HUMPHREY, J.A.C., "Numerical Calculations of developing Laminar Flow in Pipes of Arbitrary Curvatura Radius," Can. J. Chrall. [ng.. Vol. 5, 1978, pp. 151-164.

15. HUMPhREY, J.A.C., "Numerical Calrulation of Variable Property Flows in Curvilinear Orthogonal Coordinates," Can. 1. Chem. Eng., Vo1. 56, 1978, pp. 624-626.

16. LAJNDTR, B.E., nd., Studies in Convertion, Vol. 1. Aradermic Press, New York, 1975, pri. 1-78,.

17. YEE, C... "Heat. Transfer in Stromgly Curved Durt Flow," Mech. [rig. Project Report, University of California, Perkeley, 1979. 
FIGURE CAPTIONS

Fiq. I Curved duct cylindrical coordinate geometry.

Fiq. 2-a,b Comparison of elliptic (-) and parabolic (--) calculations with experimental (0) measurements of lonaitudinal velncity. Measurements are from Humphrey, et. al. [9]. $(a): z /(b / 2)=0 ;(b): z /(b / 2)=0.5$.

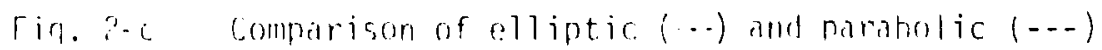
colculations of pressure at inner and outer curvature walls.

fin. 3-a,h calculated $(-)$ and masured $(0, \therefore)$ Inngitudinal velocity. Experiments are from Mori, et. al. $[12] . \quad(1):$ k. 2 De $349 ;(b) k=\sqrt{2} \mathrm{De}=876$.

liq. 3-c,d ralculated (.) and measured $(0, \hat{)}$ temperature. Experiments are from Mori, et. al. [12]. I is wall temperdure gradient. $0.49^{\circ} \mathrm{C} / \mathrm{cm}$. (c): k- Fe be $=339 ;(d): k=r^{r}$ De $=876$.

íg. 4-a Longitudinal velocity $\left(V_{\theta} / V_{B}\right)$, secondary motion $\left(\dot{V} / V_{B}\right)$ and temperature "at $\therefore 0^{\circ}$ for Case 1 in Table 1.

Fiq. 4-b Lomitudinal velocity $\left(V_{t} / V_{B}\right)$, secondary motion $\left(\hat{V} / V_{B}\right)$ and temperature" at $=45^{\circ}$ for Case 1 in Table 1 .

Fig. 1-c: Longitudinal velocity $\left(V_{i,} / V_{B}\right)$, secondary motion $\left(\vec{V} / V_{B}\right)$ and temperature is at $=90^{\circ}$ for Case 1 in Table 1 .

fir. A-d Longitudinal velocity $\left(V_{\phi} / V_{B}\right)$, secondary motion $\left(\vec{V} / V_{B}\right)$ and temperature $A$ at $\dot{w}=90^{\circ}$ for Case 2 in Table 1 .

Fig. 4-e Longitudinal velocity $\left(V_{\phi} / V_{B}\right)$, secondary motion $\left(\vec{V} / V_{B}\right)$ and temperature $a$ at $\ddagger=90^{\circ}$ for Case 3 in Table 1 .

rii. 4-f Longitudinal velocity $\left(V_{\phi} / V_{B}\right)$, secondary motion $\left(V / V_{B}\right)$ and temperature $?$ $:=90^{\circ}$ for Case 7 in Table $?$. 
Fig. 4-q Temperature at 90" for Cases 10, 11 and 12 in Table 1.

Fig. 4-h longitudinal velocity $\left(V_{t,} / V_{B}\right)$, secondary motion $\left(V / V_{B}\right)$ and temperature ", at : $-90^{\circ}$ for Case 13 in Table 1.

Гiq. 5- Pressure loss curves for case studies in Table 1.

Fig. 5-b rriction coefficient curver for case studies in Table 1.

「ia. 6-a Longitudinal variation of Nusselt and temperature for different. De.

fig. 6-b Longitudinal variation of Nusselt for different b/a (Cases $1,2,3$ ) and for different temperature and velocity entrance conditions (Cases $7,8,9$ ).

fig, 6-c Longitudinal variation of Nusselt and temperature for individually heated walls. 


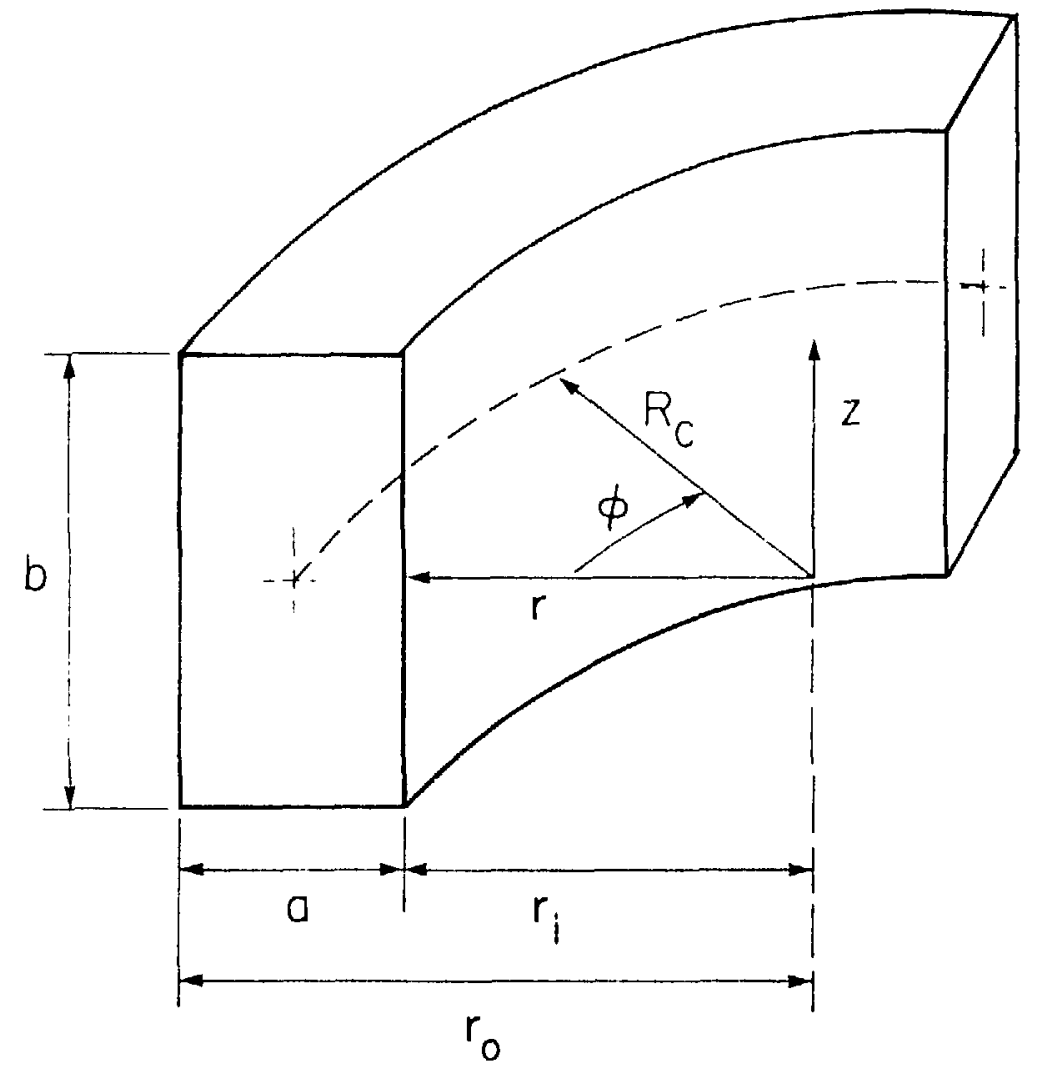

FIGURE 1 
26

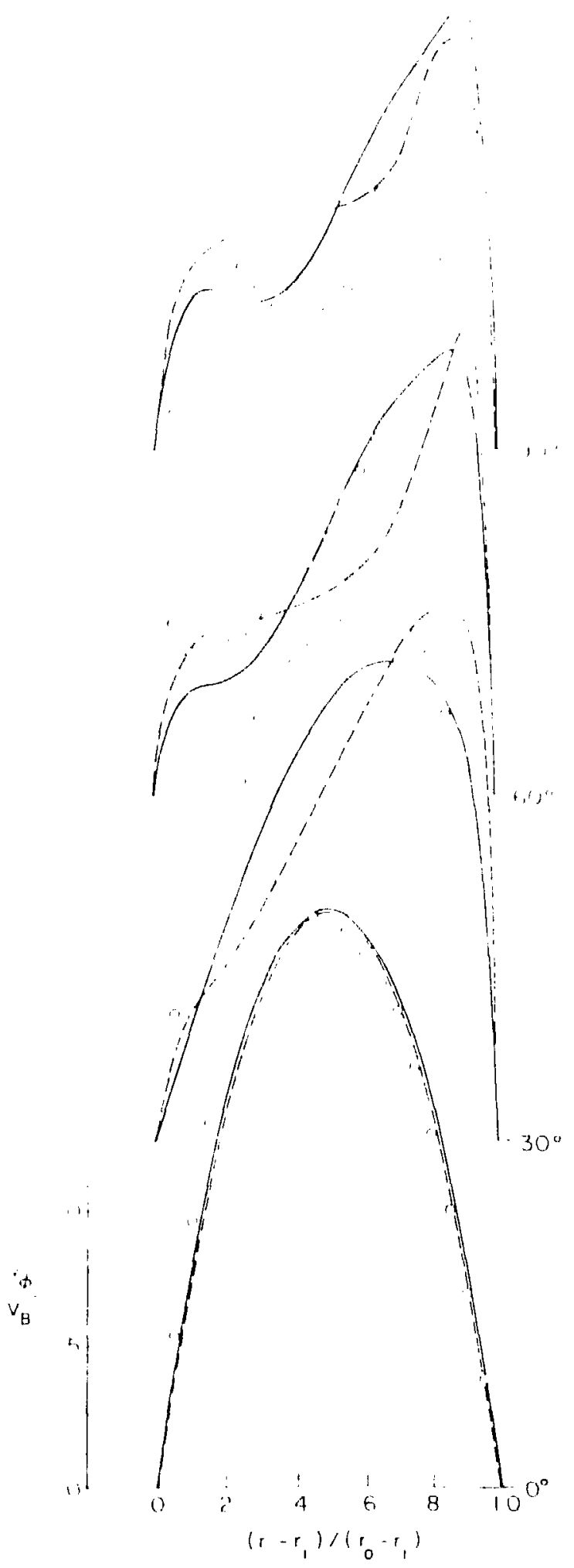

(a)

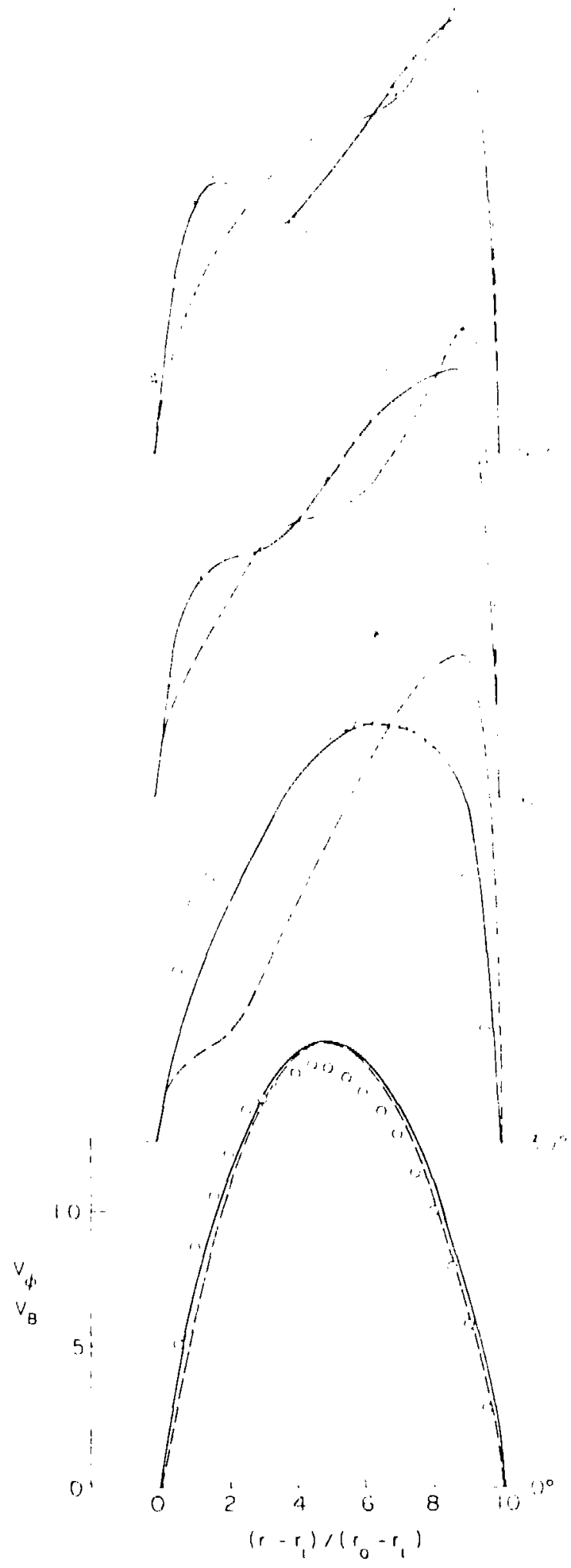

(b)

FIGURE $2-a, b$ 


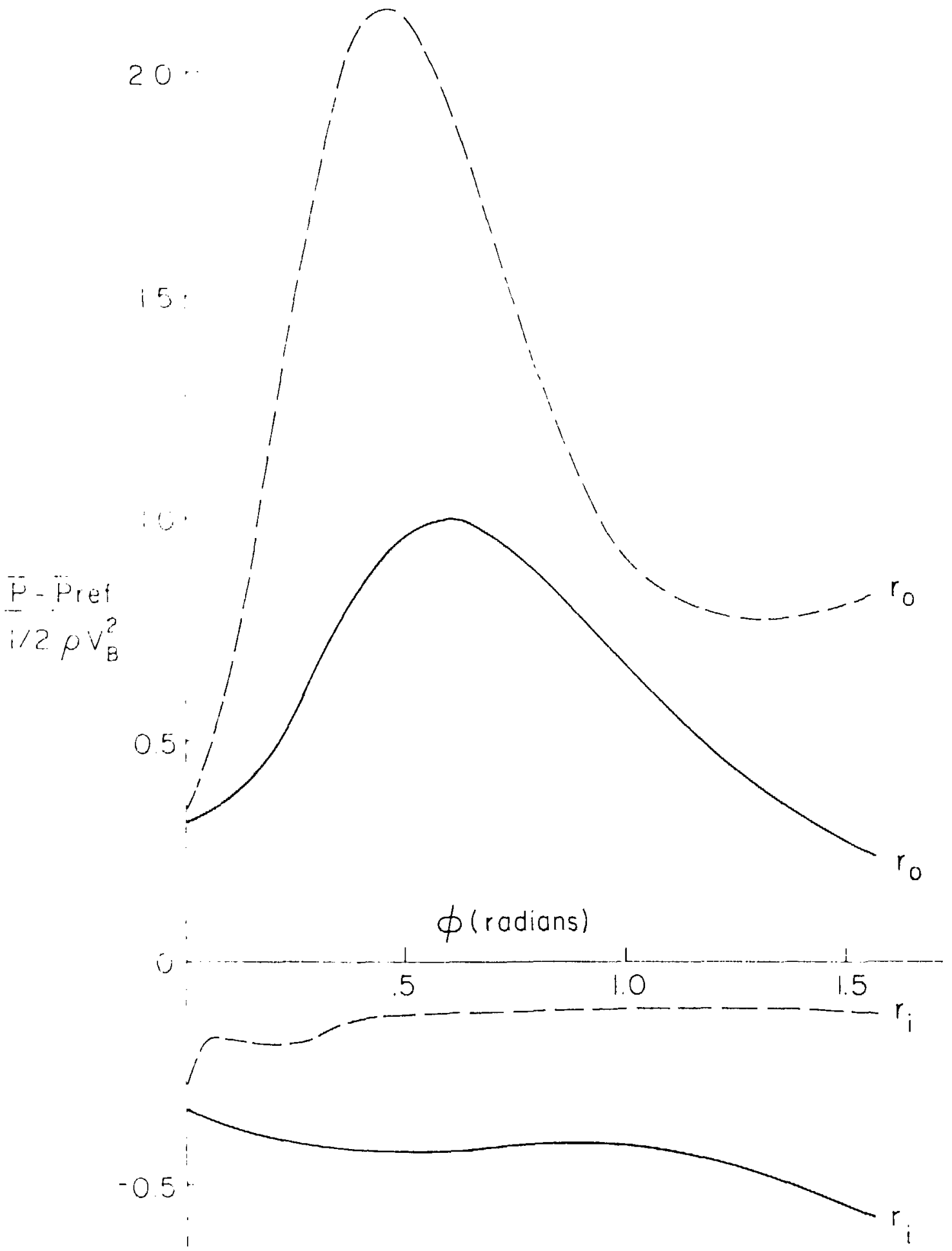

FIGURE 2-C 
$28-a$.

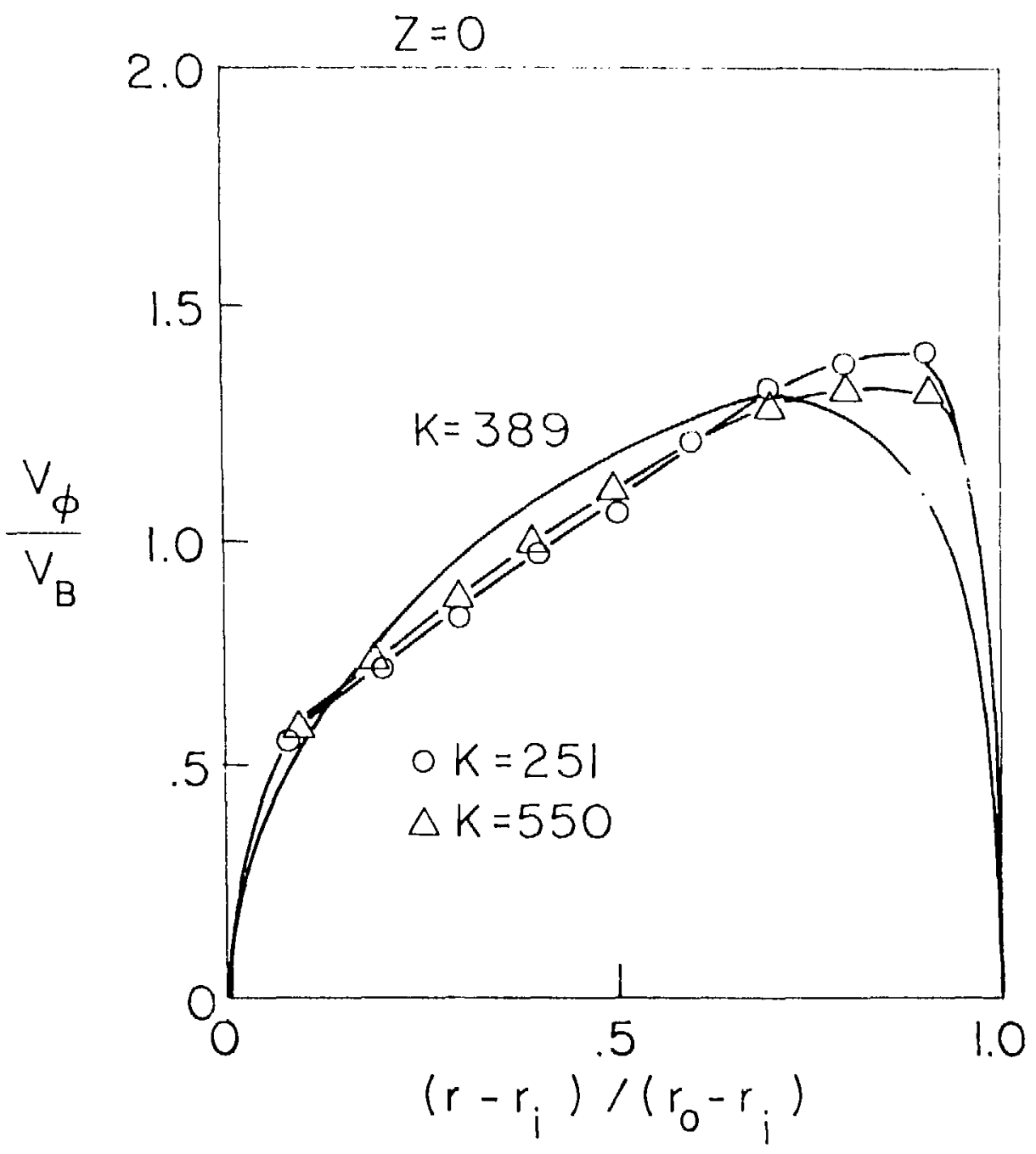

FIGURE 3-a 
28-b.

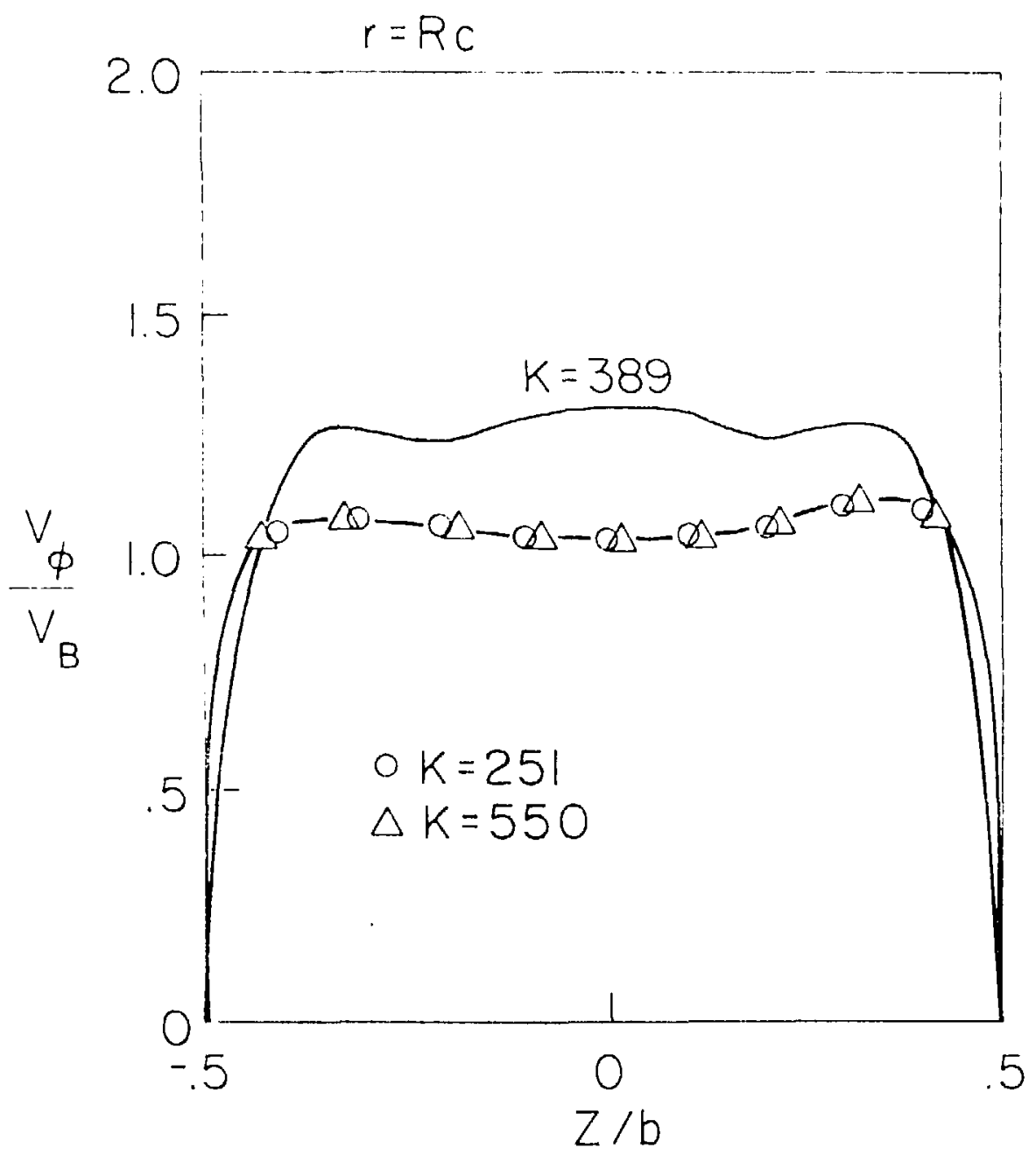

FIGURE 3-a 


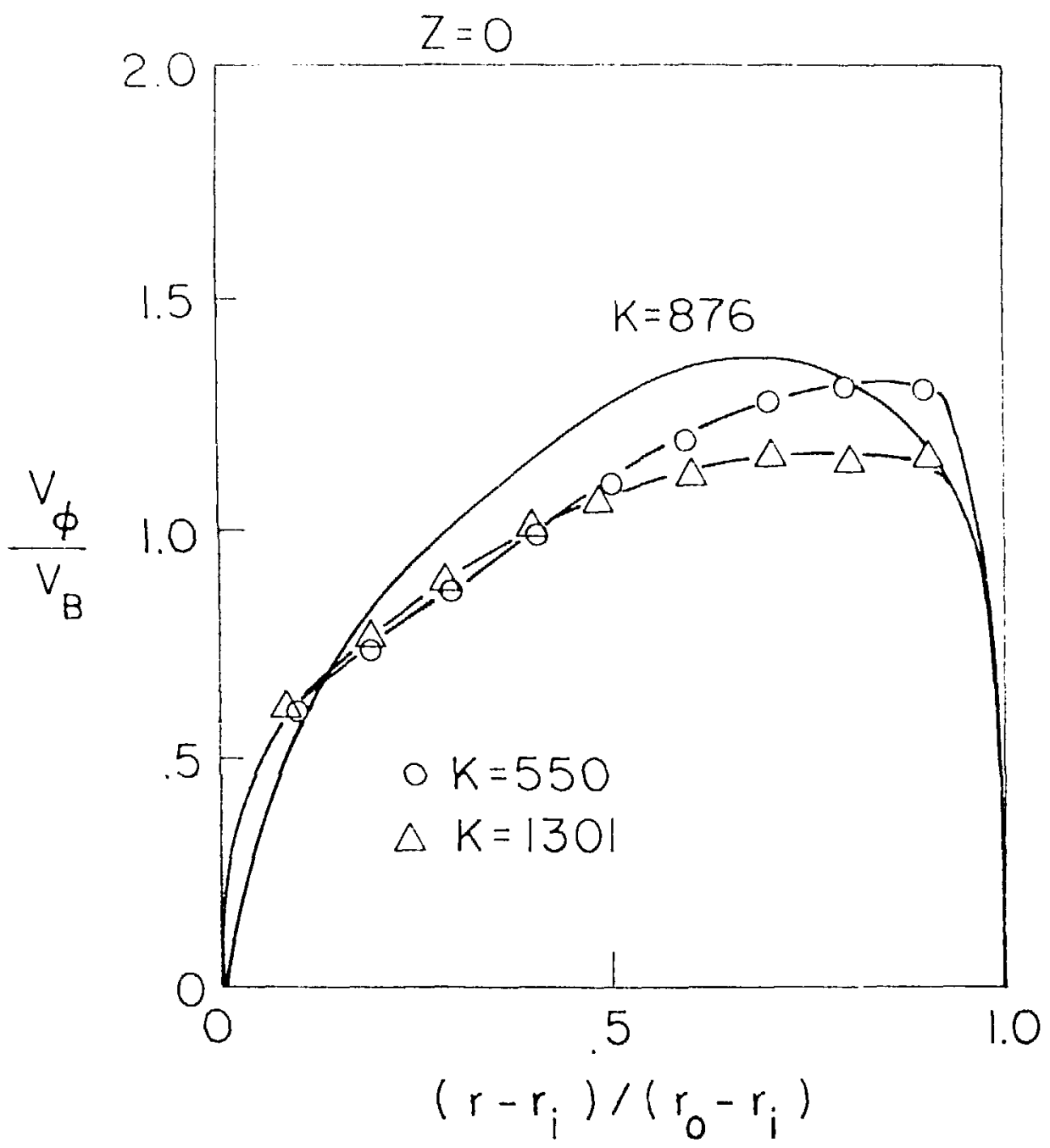

FIGURE 3-b 
29-b.

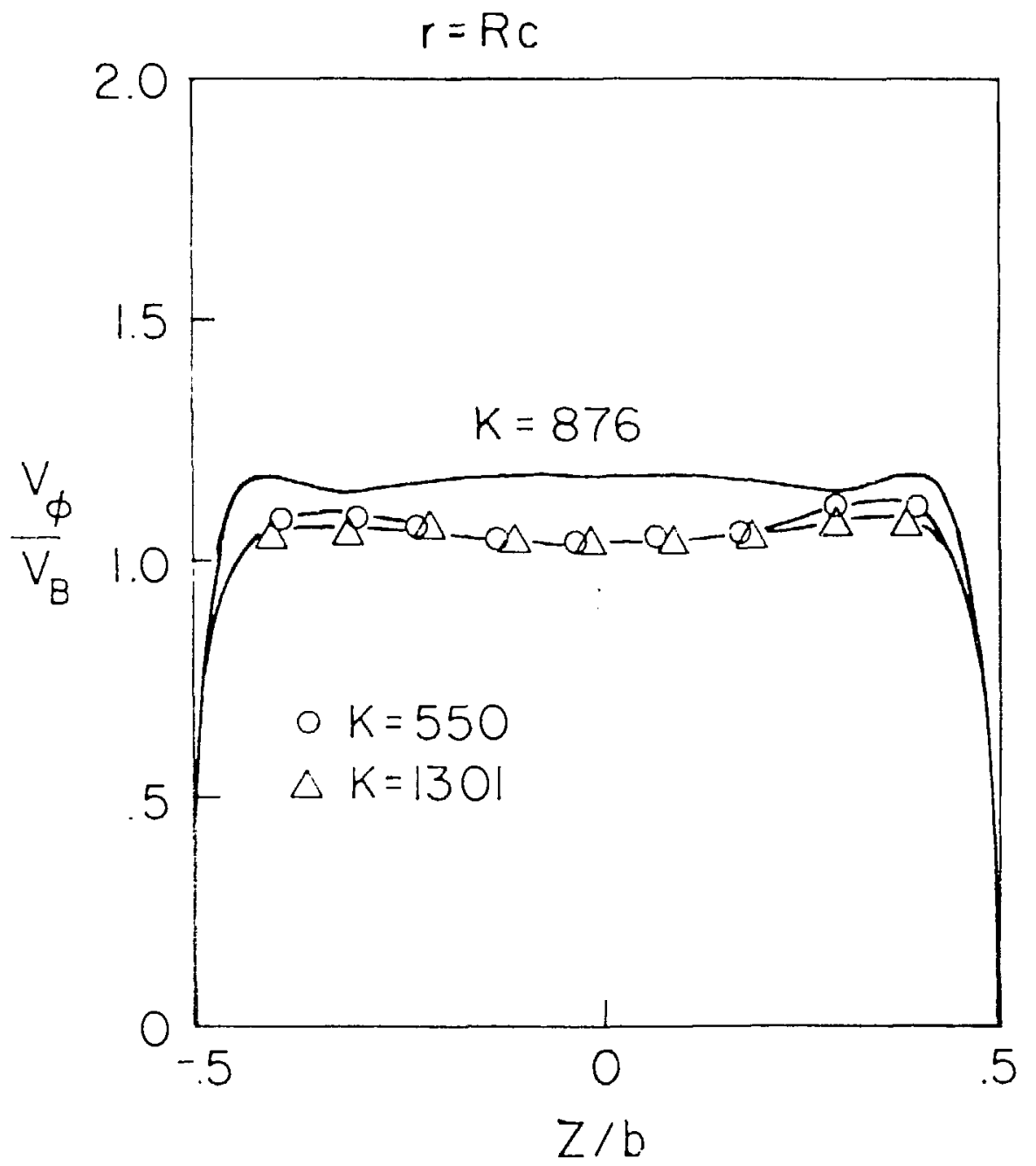

FIGURE 3-b 
$30-a$.

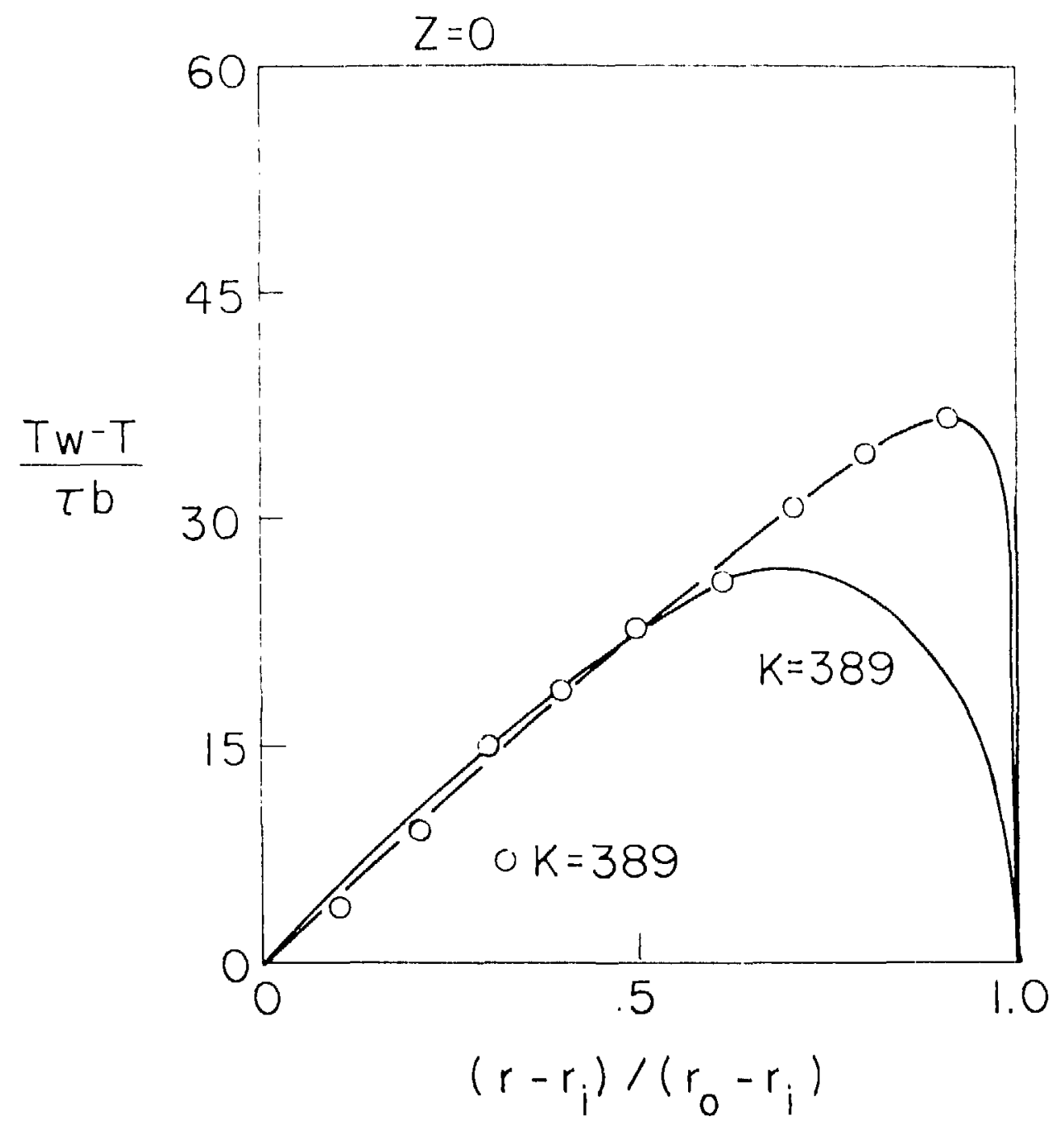

FIGURE $3-\mathrm{C}$ 


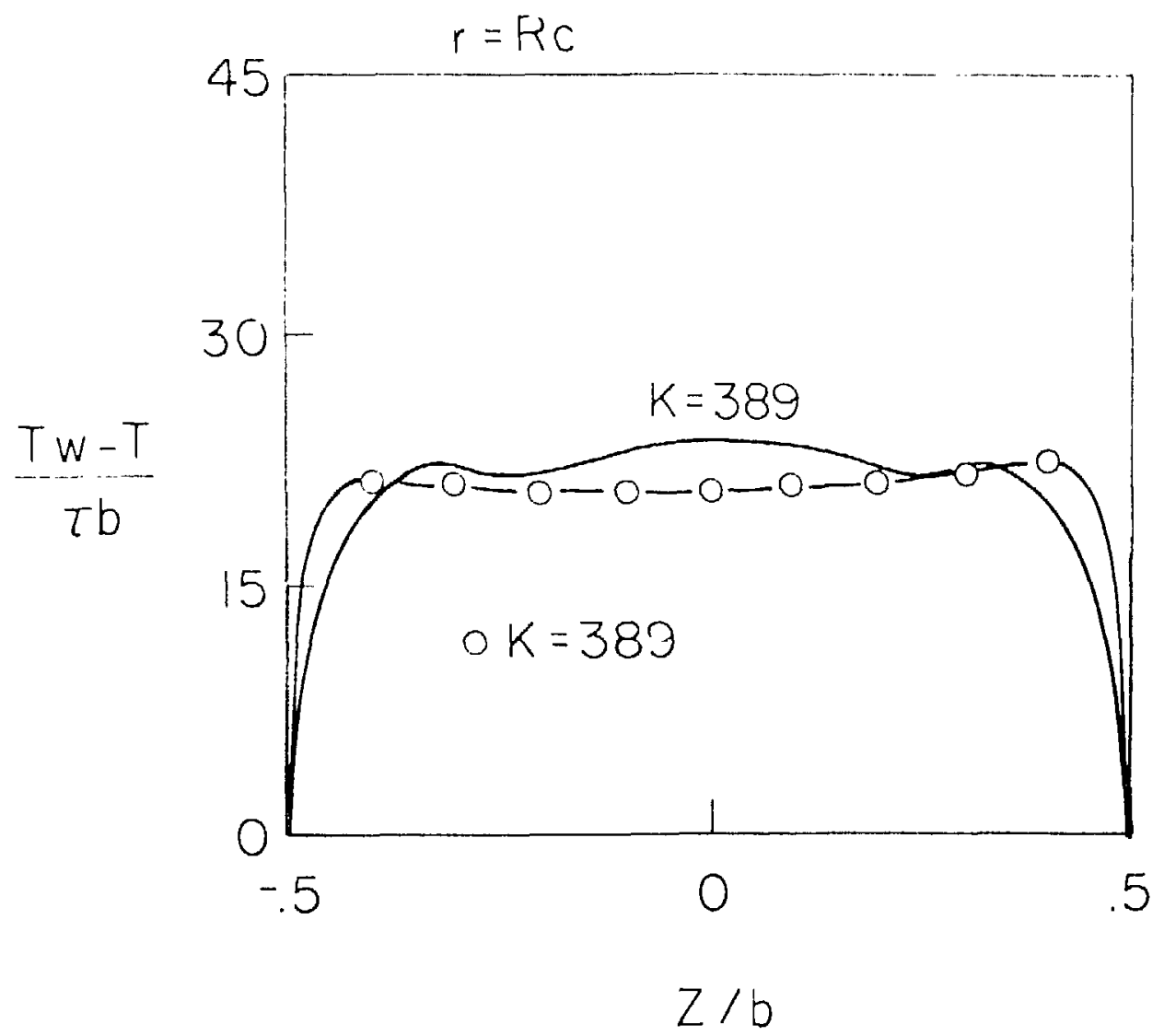

FIGURE 3-C 
3]-a.

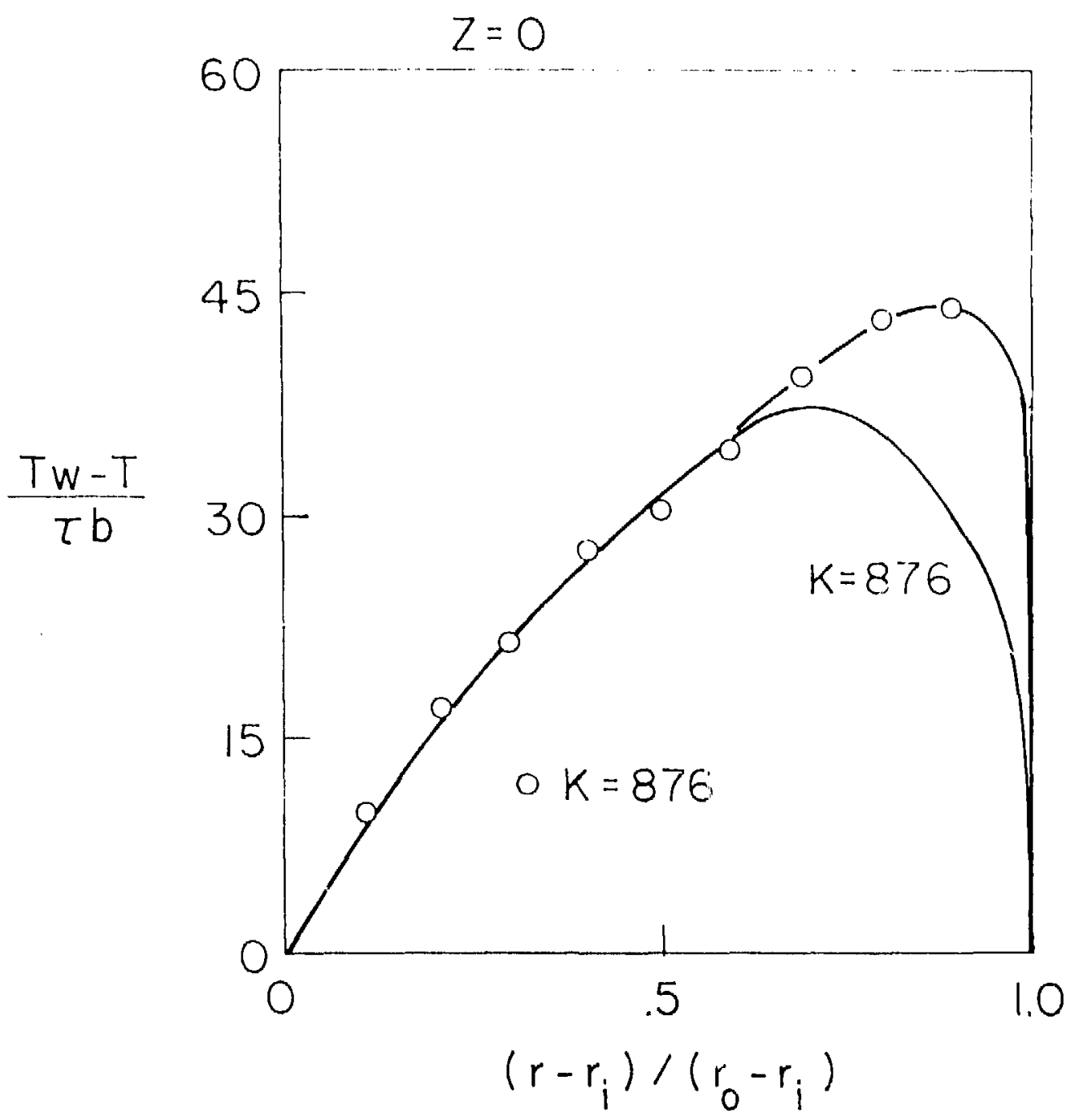

FIGURE 3-d 
$3 i-b$

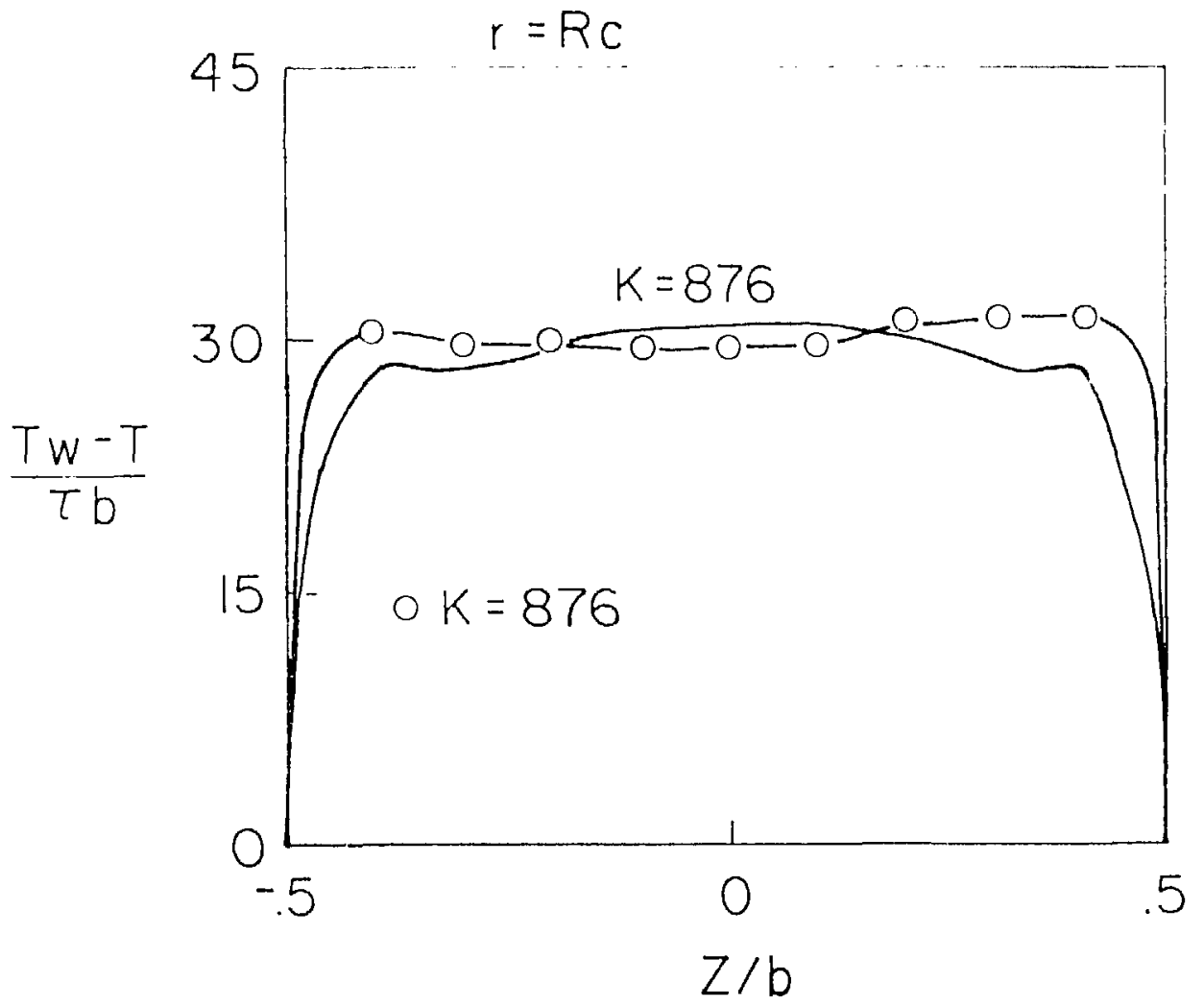

FIGURE 3-d 


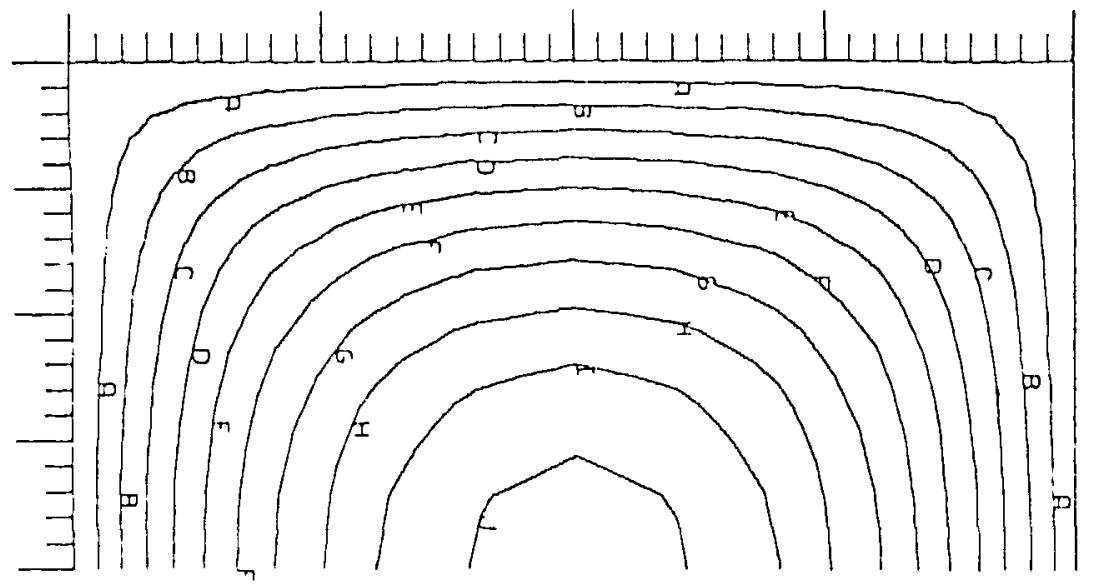

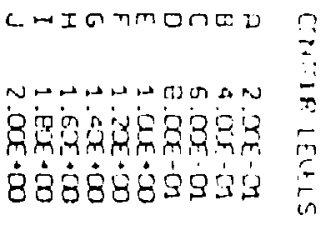

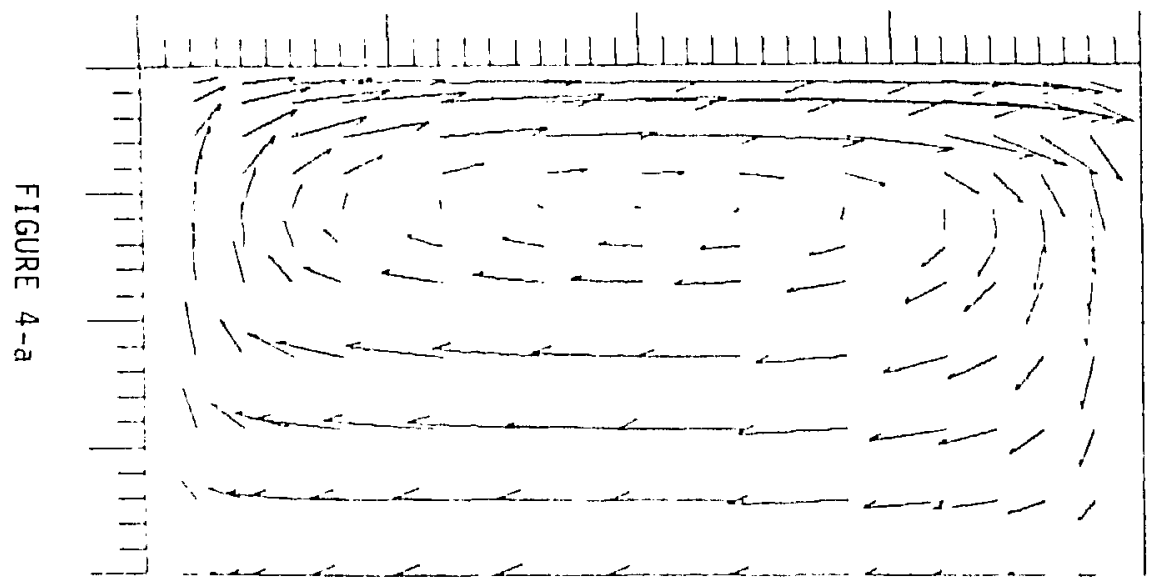

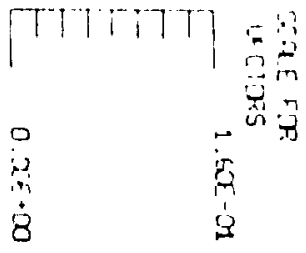

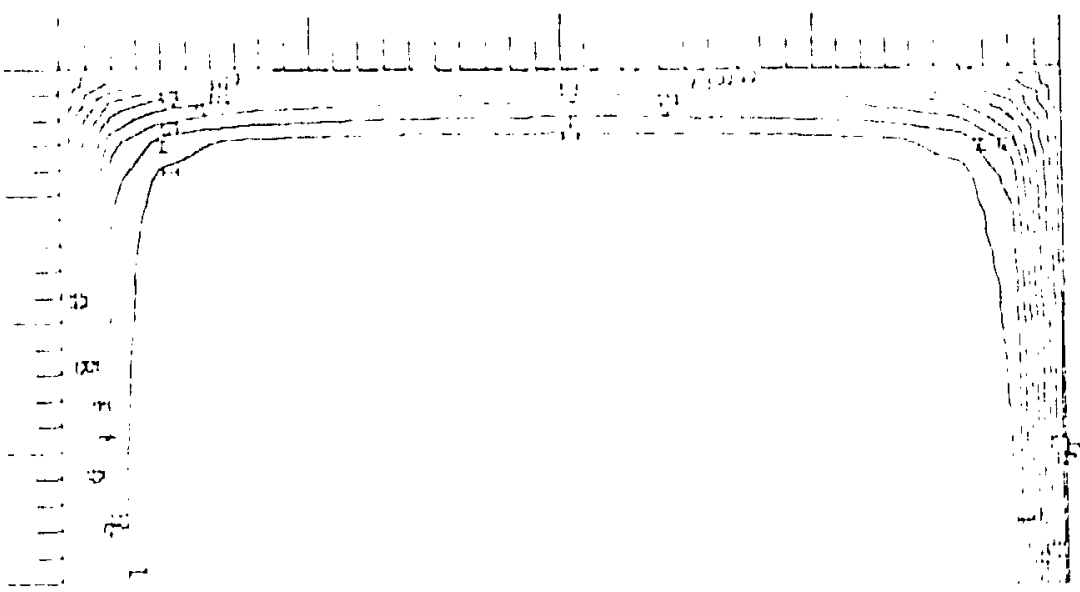

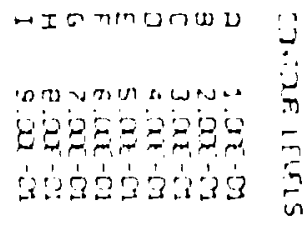



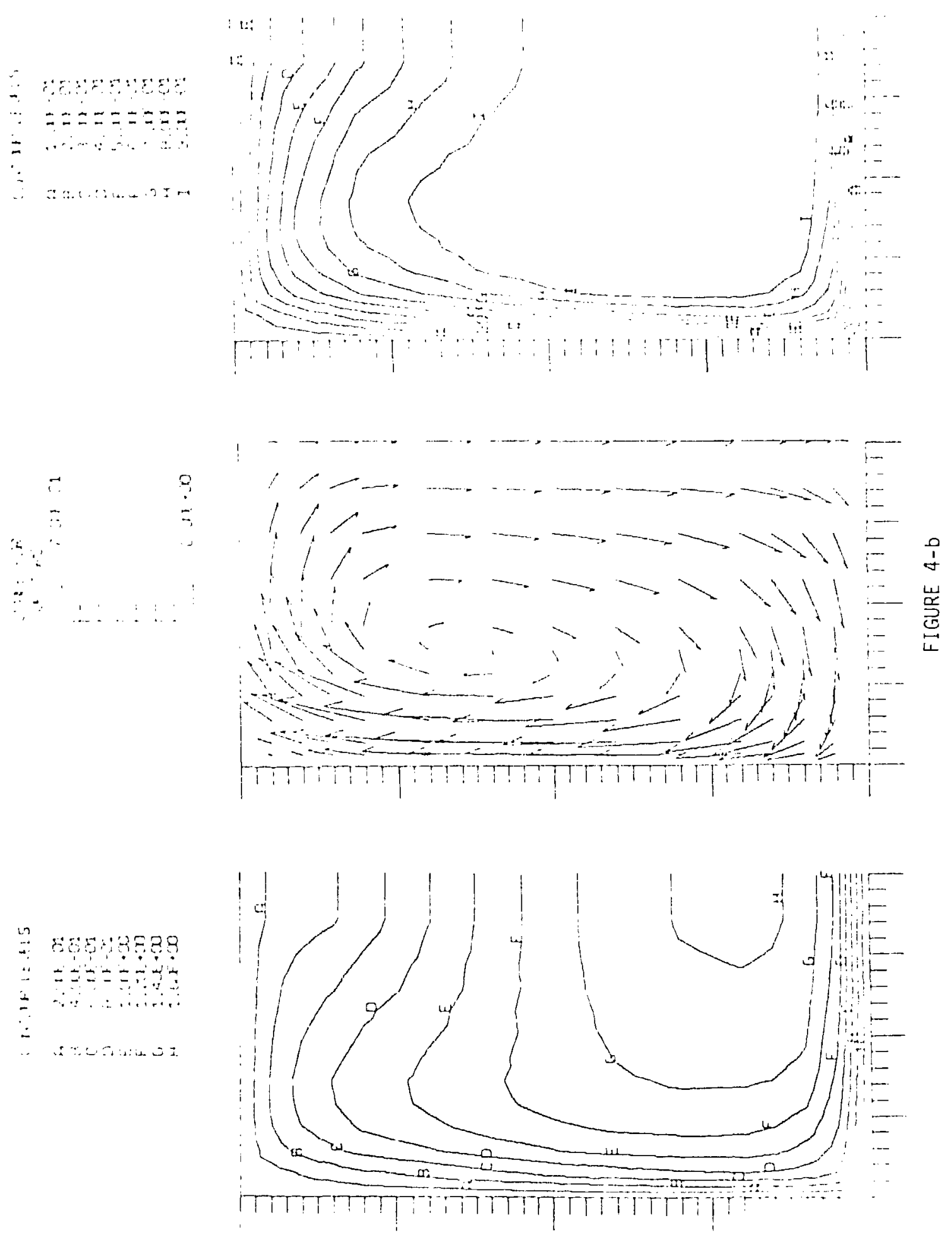

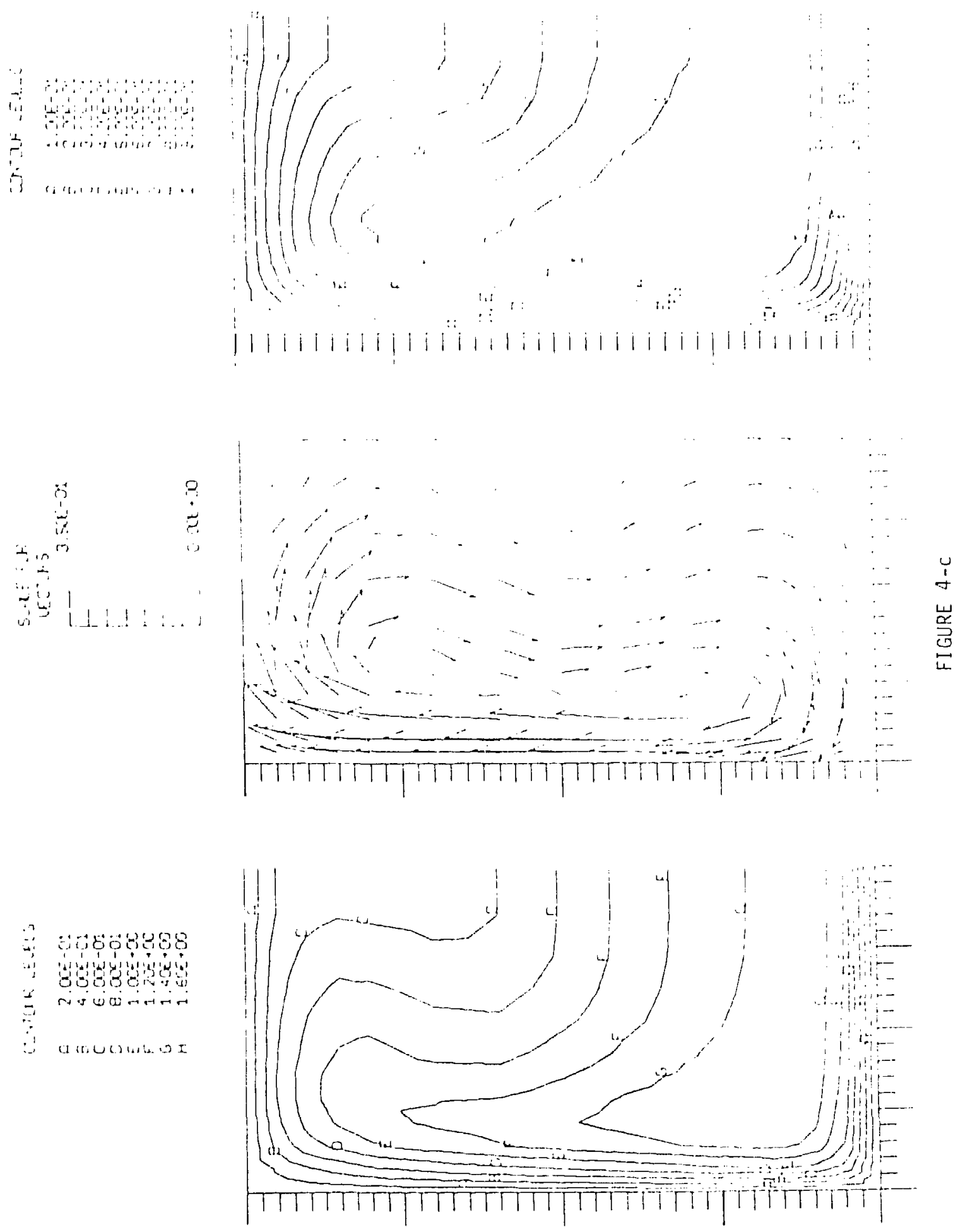
35.
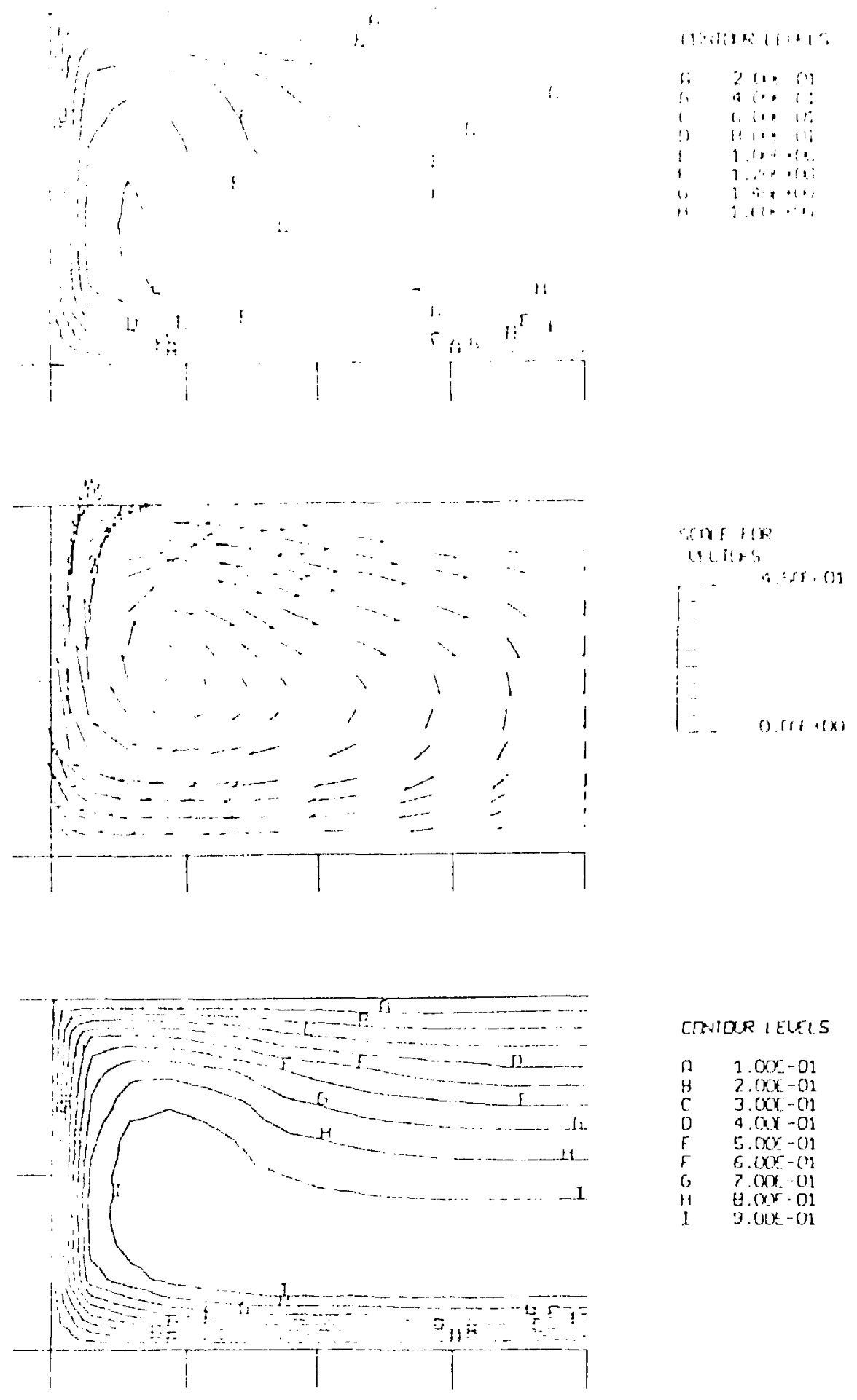

CTHIOR I EUTS

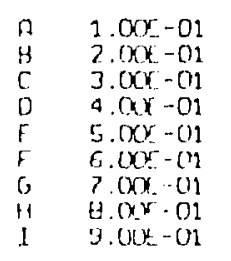

FIGURE 4-d 

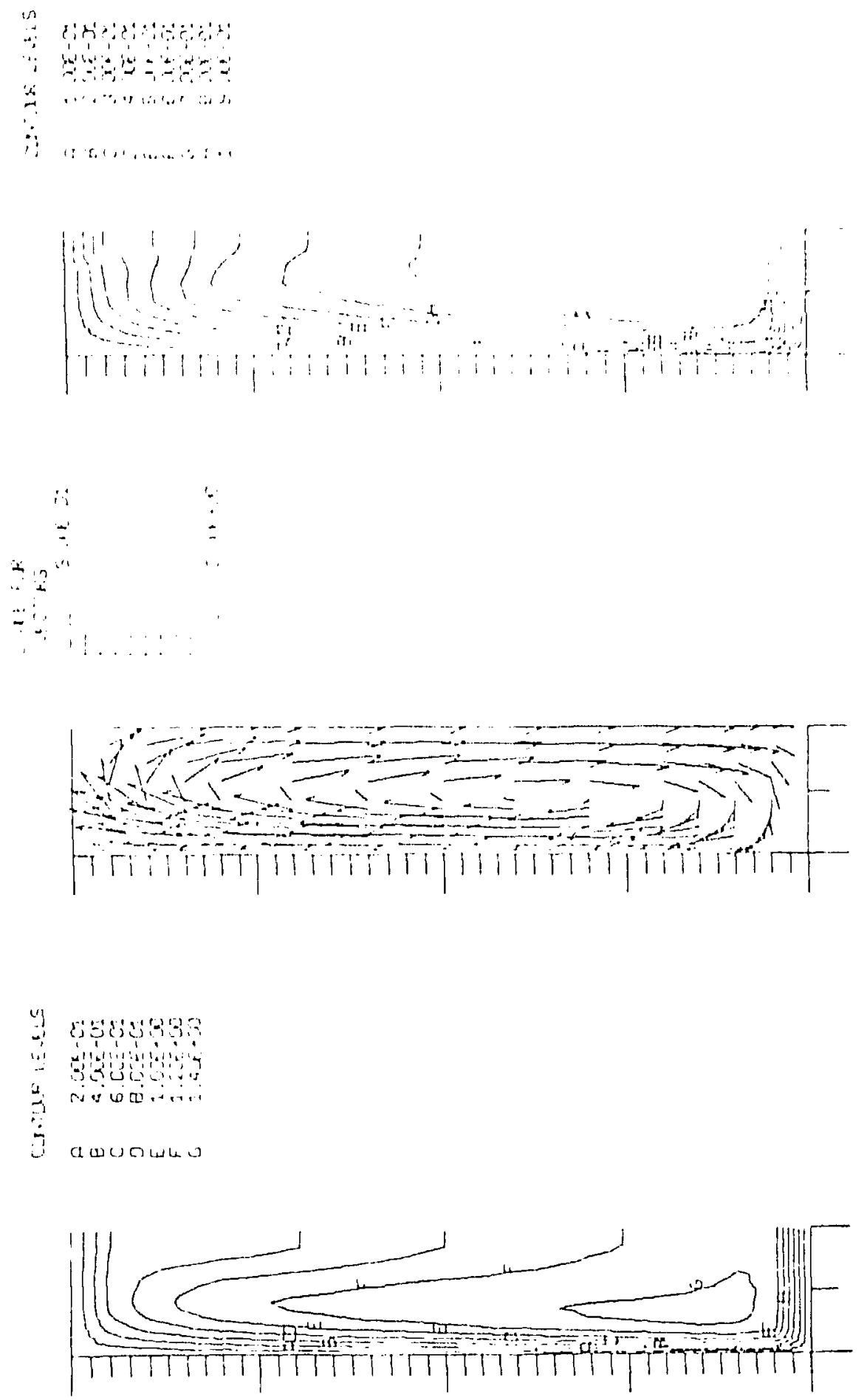
37.
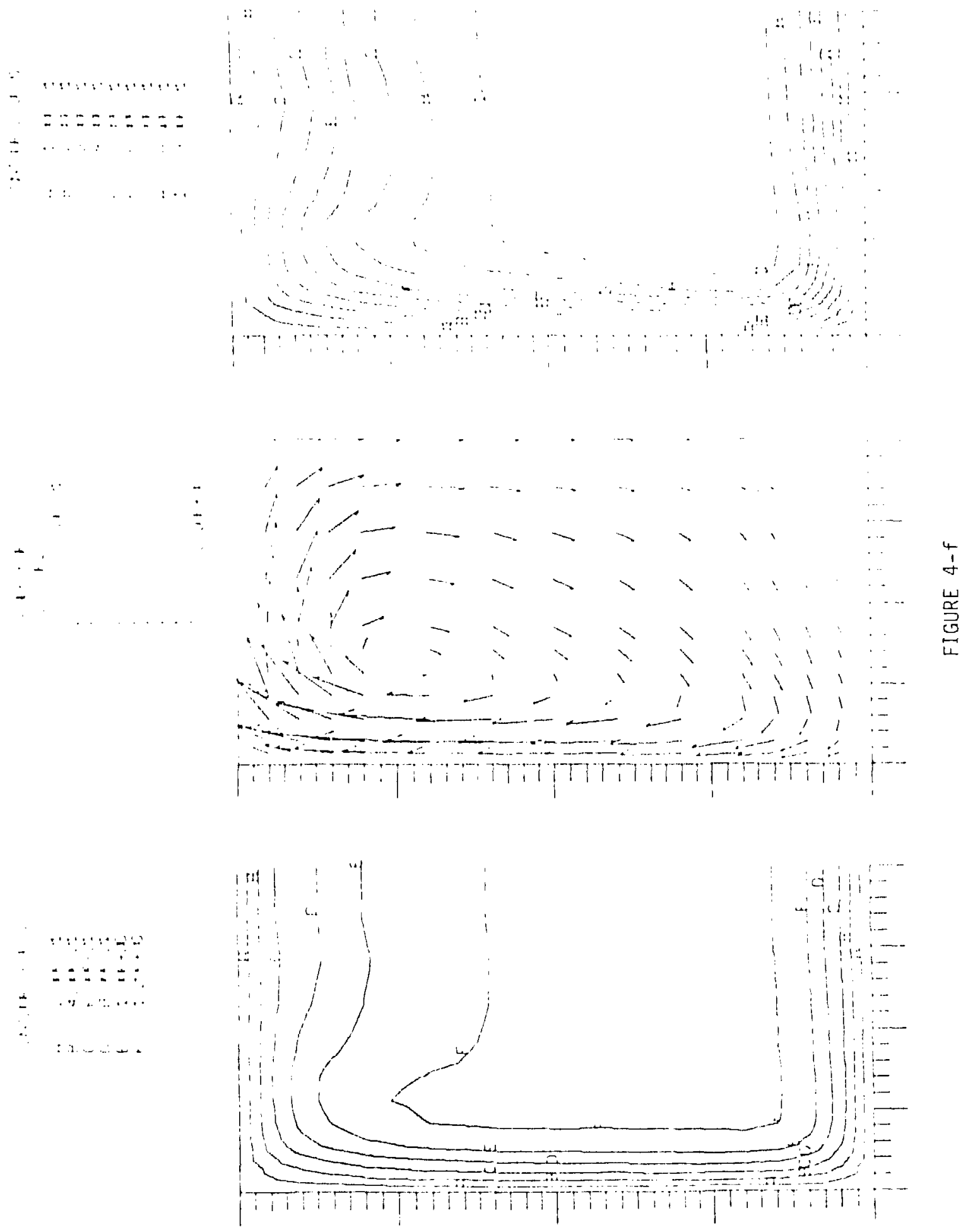

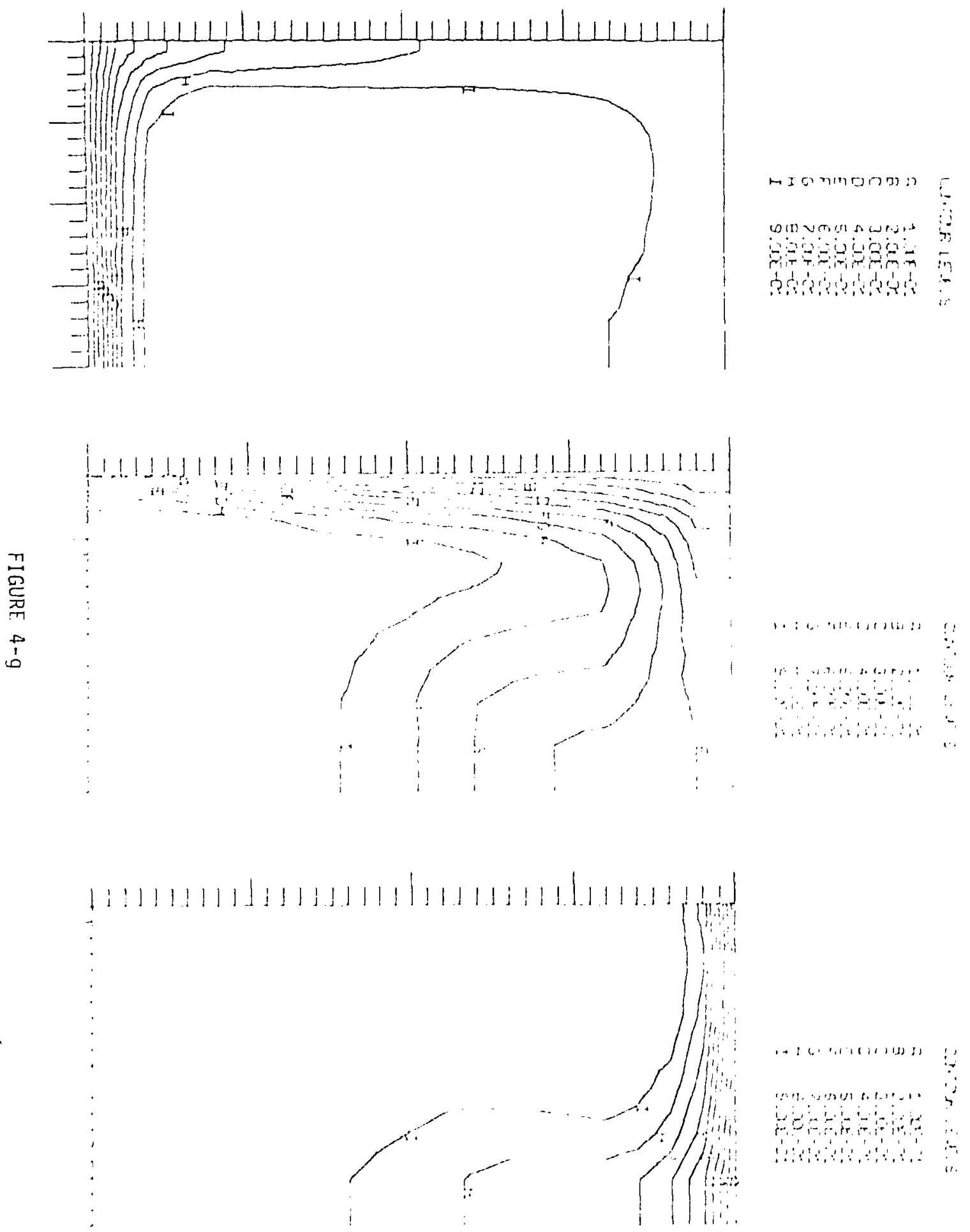

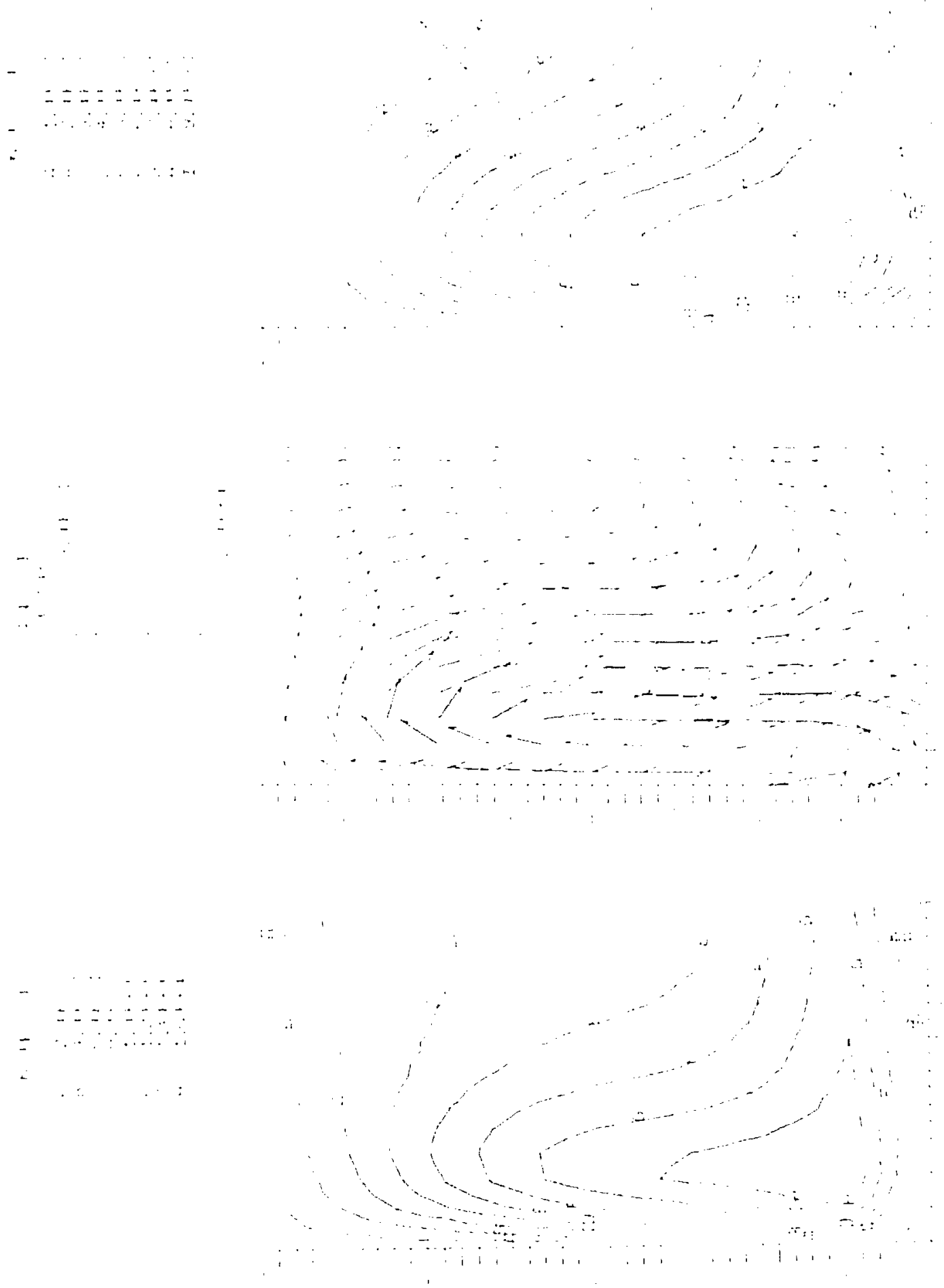
40.

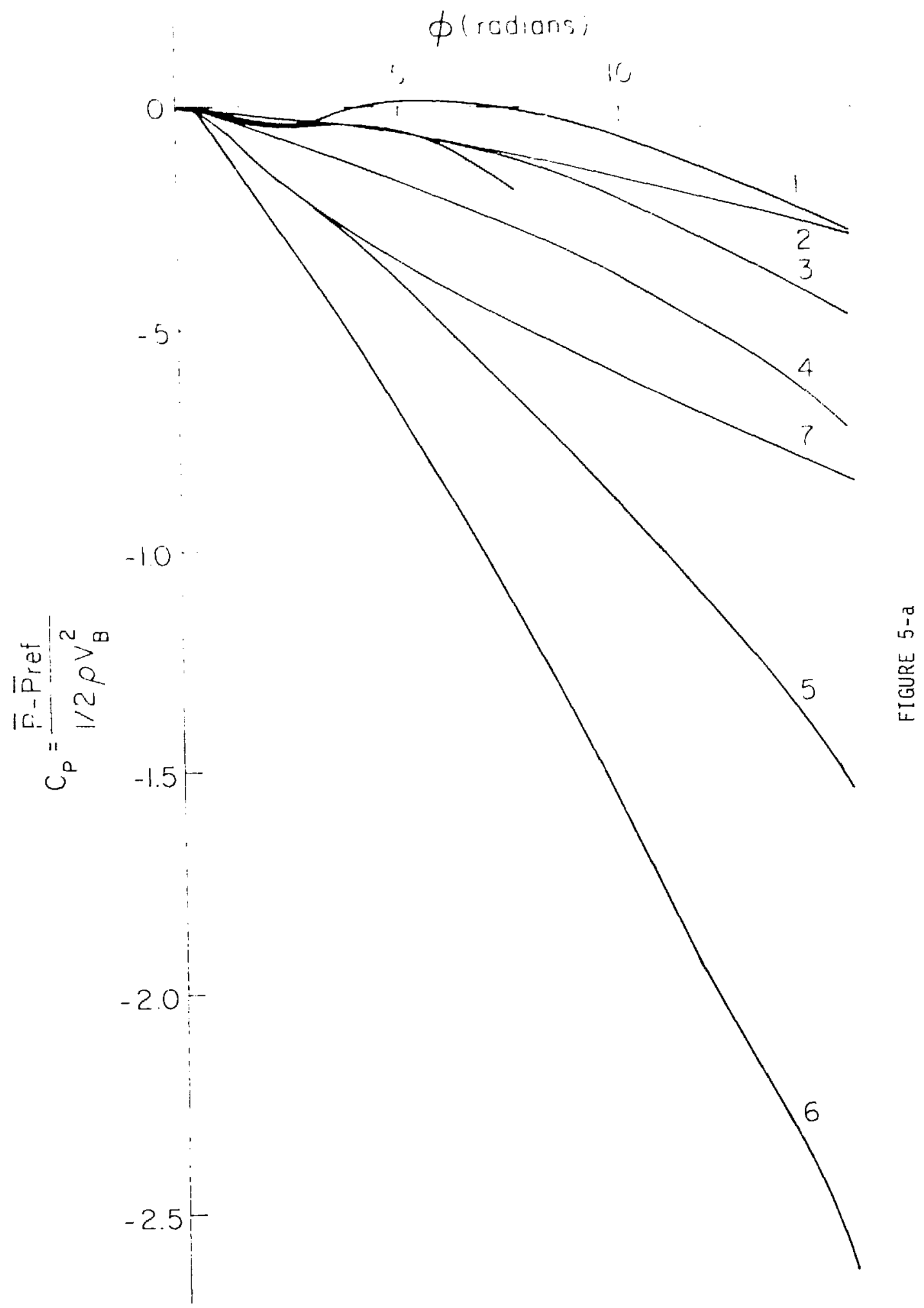




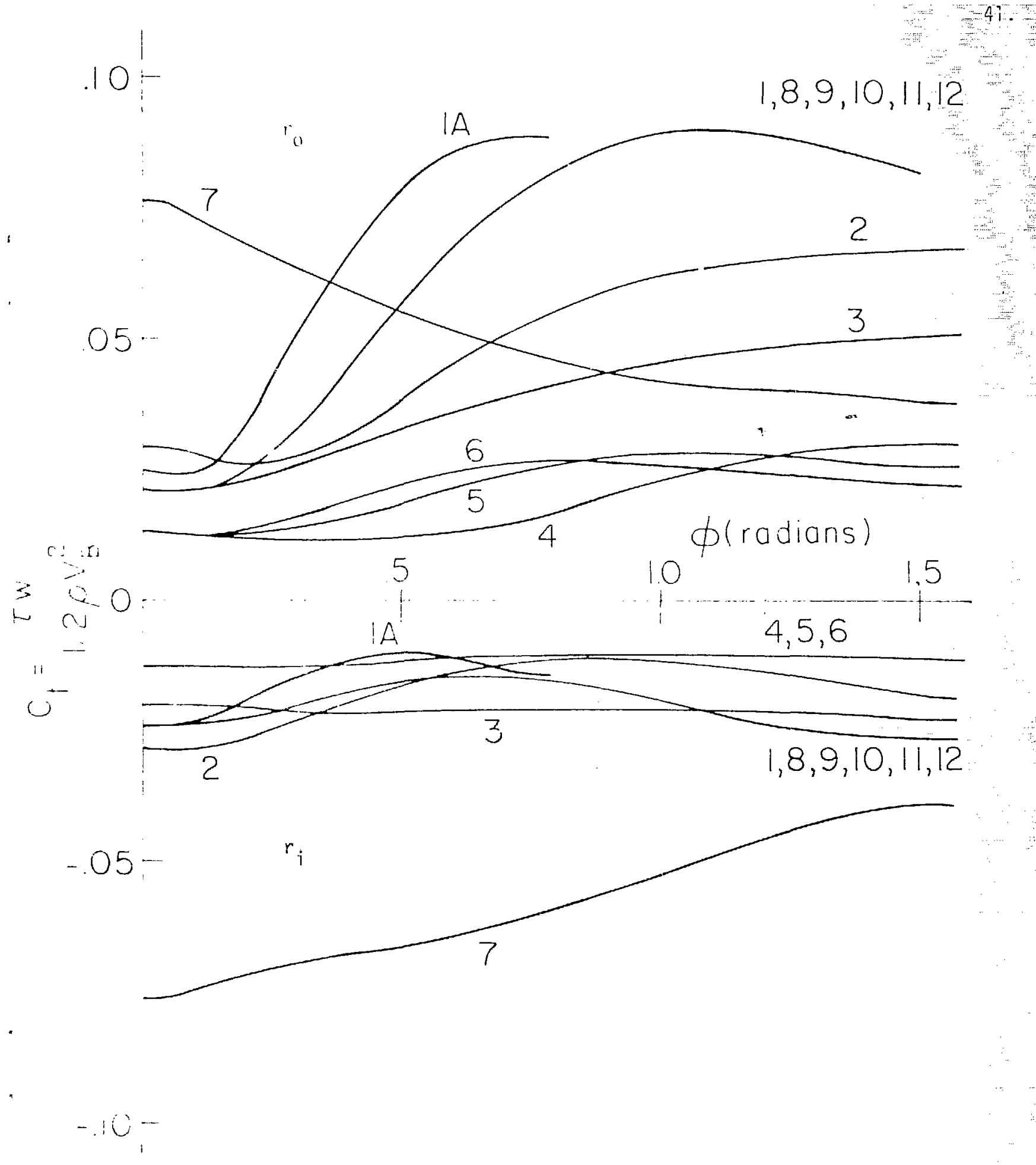

FIGURE 5-b 
42.

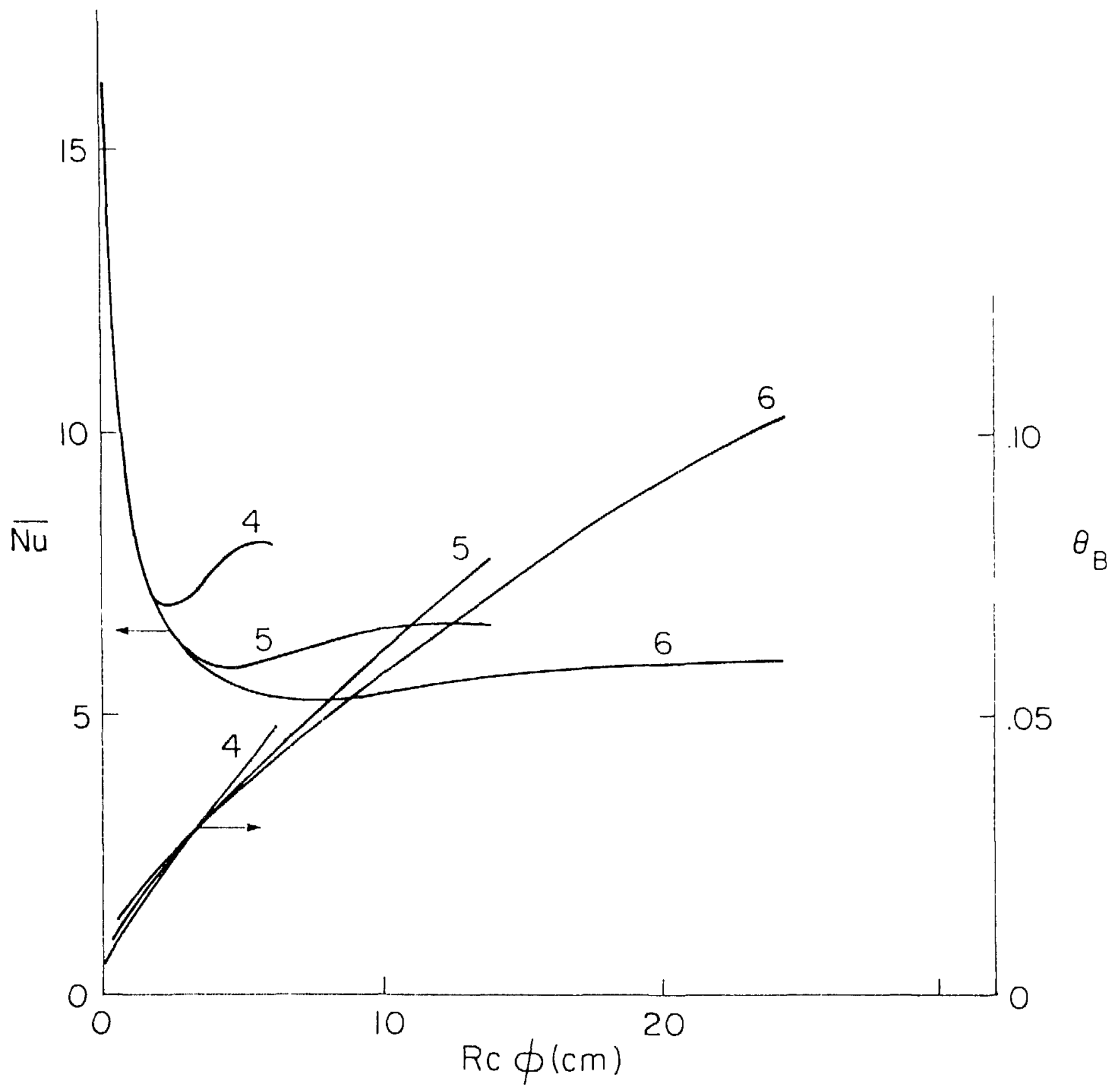

FIGURE $6-a$ 
43.

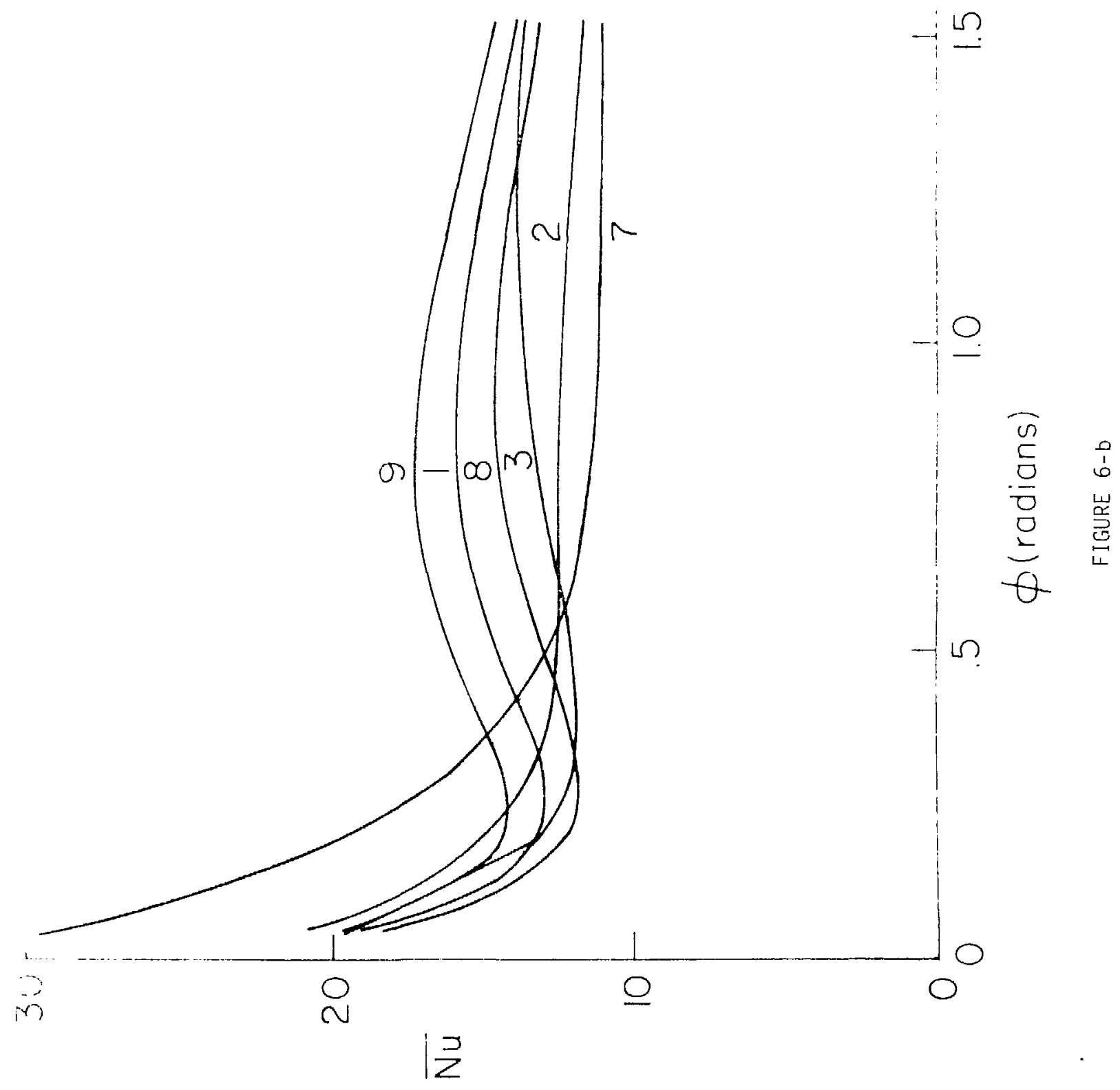




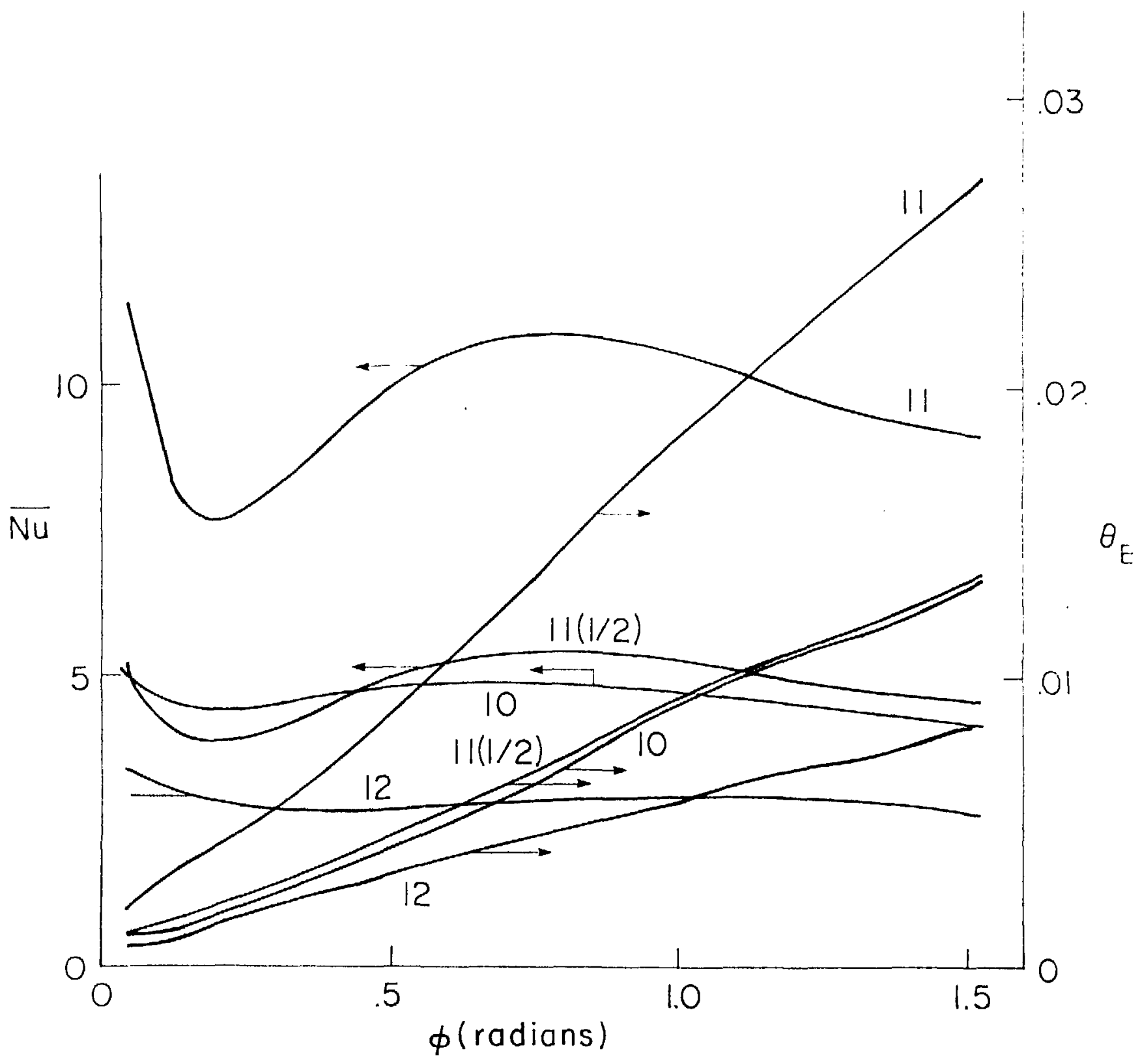

FIGURE 6-C 